\title{
Termal Uydu Görüntülerinden Üretilen Yer Yüzeyi Sıcaklığı ile Hava Sıcaklığı İlişkisinin Değerlendirilmesi
}

\author{
Murat Türkyilmaz ${ }^{1}$, Emre Özelkan ${ }^{1,2}$, Muhittin Karaman ${ }^{3}$ \\ 1*Çanakkale Onsekiz Mart Üniversitesi, Lisansüstü Eğitim Enstitüsü, Doğal Afetlerin Risk Yönetimi Anabilim Dalı, 17020 Çanakkale / Türkiye (ORCID: 0000-0002- \\ 3545-3988), muratrkylmz@gmail.com \\ ${ }^{2}$ Çanakkale Onsekiz Mart Üniversitesi, Şehir ve Bölge Planlama Bölümü, 17020, Çanakkale/ Türkiye (ORCID: 0000-0002-2031-1610), emreozelkan @ comu.edu.tr \\ 3 3İstanbul Teknik Üniversitesi, Maden Fakültesi, Jeoloji Mühendisliği Bölümü, 34469, İstanbul/Türkiye (ORCID: 0000-0002-8971-010X), m.karaman@itu.edu.tr
}

(İlk Geliş Tarihi 5 Eylül 2020 ve Kabul Tarihi 30 Aralık 2020)

(DOI: $10.31590 /$ ejosat.799722)

\begin{abstract}
ATIF/REFERENCE: Türkyılmaz, M., Özelkan, E., \& Karaman, M. (2020). Termal Uydu Görüntülerinden Üretilen Yer Yüzeyi
\end{abstract} Sıcaklığı ile Hava Sıcaklığı İlişkisinin Değerlendirilmesi. Avrupa Bilim ve Teknoloji Dergisi, (20), 932-948.

\section{$\ddot{O} \mathbf{z}$}

Yer Yüzeyi Sıcaklığı (YYS) yerelden küresele yeryüzündeki arazi örtüsü ve kullanımı değişimlerinin incelenmesinde anahtar parametrelerden biridir. Uzaktan algılama yöntemleri ile termal uydu görüntülerinden üretilen YYS değerlerinin, meteoroloji istasyonlarında ölçülen hava sıcaklığı verileri ile ilişkilendirilmesi ve doğruluğunun belirlenmesi gerekmektedir. Bu çalışmada farklı yöntemlerle Landsat uydusunun termal verilerinden elde edilen YYS değerlerinin, hava sıcaklığını ne kadar temsil ettiği incelenmiştir. İnceleme alanı olarak Çanakkale İli tercih edilmiş̧ir. Çalışmada, Çanakkale ilinin 1984 ile 2019 yılları arasındaki (2002, 2006, 2012, 2017 yılları haricinde) her Temmuz ayında temin edilen 66 adet Landsat uydu görüntüsünün termal verileri kullanılarak çok zamanlı YYS değişimi incelenmiştir. YYS değerleri, atmosferik su buharı içeriği ve hava sıcaklığı gibi girdi parametrelerine ihtiyaç duymadan çalışan yöntemlerden Artis \& Carnahan Denklemi ve tek kanal yöntemlerinden Radyatif Transfer Denklemi, Tek kanal Denklemi, Tek Pencere Denklemi ile hesaplanmıştır. Denklemlerin YYS değerlerinin hesaplanması için Landsat uydularının termal verileri, Landsat uydu görüntüleri ile eş zamanlı hava sıcaklık değerleri, Normalize Edilmiş Bitki Örtüsü Fark İndisi (NDVI) ve atmosferik etkenler (yükselen 1şınım, alçalan 1şııım ve atmosferik geçirgenlik) kullanılmışıır. Hesaplanan YYS değerleri 12 farklı meteoroloji istasyonundan temin edilen eş zamanlı saatlik yersel veriler ile kıyaslanmıştır. Çalışmada gerçekleştirilen uygulama üç adımda sıralanabilir; 1) YYS değerlerinin Artis \& Carnahan, Tek Kanal, Tek Pencere, Radyatif Işıma Denklemleri ile hesaplanması, 2) Oluşturulan YYS değerlerinin doğruluğunu belirlemek için meteoroloji istasyonlarından alınan Landsat uydu görüntüleri ile eş zamanlı hava sıcaklık verileri ile karşılaştırılması ve en başarılı yöntemin regresyon - korelasyon analizi ve kök ortalama karesel hata (RMSE) ile belirlenmesi, ve 3) Arazi örtüsü ve kullanımı ve yapısı ile YYS ilişkisinin incelenmesi. Regresyon - korelasyon değerlerine göre tüm yöntemler birbirine çok yakın çıkmış ve başarı sıralaması Tek Kanal, Tek Pencere, Radyatif Transfer ve Artis \& Carnahan şeklindedir. RMSE değerleri yöntemlerin başarı sıralamasının tespitinde daha belirleyicidir. RMSEmin ve RMSEort değerlerine göre yöntemlerin başarı sıralaması ise Artis \& Carnahan, Tek Pencere, Tek Kanal, Radyatif Transfer Denklemi şeklindedir. YYS değerleri ormanlık alanlar, park alanları ve yeşil alanlarda en düşük değerlere ulaşırken, en yüksek değerlere betonarme ve asfalt yapıların yoğun olduğu kentsel alanlarda ve boş arazilerde ulaşılmıştır. NDVI, YYS ile negatif bir korelasyona sahiptir. Elde edilen bulgular termal görüntülerden üretilen YYS verisinin arazi örtüsünün ve arazi kullanımının yorumlanmasında önemli bir kaynak olduğunu göstermektedir.

\section{Evaluation of the Relationship between Land Surface Temperature Derived from Thermal Satellite Images and Air Temperature}

\begin{abstract}
Land Surface Temperature (LST) is one of the key parameters in the analysis of land cover and use changes on the earth from local to global. It is necessary to correlate the LST values produced by remote sensing methods from thermal satellite images with the air temperature data measured at meteorology gauging stations and to determine their accuracy. In this study, to what extent the LST values obtained from the thermal data of the Landsat satellite with different methods represent the air temperature, was examined. Çanakkale Province was chosen as the research area. In the study, multi-temporal LST change was examined using the thermal data of 66 Landsat satellite images obtained in every July between 1984 and 2019 (except for 2002, 2006, 2012, 2017) in Çanakkale
\end{abstract}


Province. LST values are calculated using Artis \& Carnahan Equation that works without the need for input parameters sucs as atmospheric water vapor content and air temperature, and single methodsRadiative Transfer Equation, Single Channel Equation, Single Window Equation, which are methods that work without the need for input parameters such as atmospheric water vapor content and air temperature. Thermal data of Landsat satellite, simultaneous air temperature values with Landsat satellite images, Normalized Vegetation Difference Index (NDVI) and atmospheric factors (upwelling atmospheric radiance, downwelling atmospheric radiance, total atmospheric transmissivity) were used to calculate the LST values. The LST values in the study were compared with the simultaneous hourly data obtained from 12 different local meteorology stations. The application performed in the study can be listed in three steps; 1) Calculation of LST values with Artis \& Carnahan, Single Channel, Single Window, and Radiative Radiation Equations, and 2) Comparison of air temperature data of local meteorology stations, which is simultaneous to Landsat acquiraion time to determine the accuracy of the generated LST values, and determination of the most successful method by regression-correlation analysis and root mean square error (RMSE), and 3) Examining the relationship between land use/cover and LST. According to the regression-correlation values, all methods are very close to each other and the success order is as Single Channel, Single Window, Radiative Transfer and Artis \& Carnahan. RMSE values are more determinant in determining the success ranking of the methods. According to RMSEmin and RMSEort values, the success order of the methods is Artis \& Carnahan, Single Window, Single Channel, and Radiative Transfer Equation. LST values reached the lowest values in forestlands, park areas and green areas, while the highest values reached in urban areas which have high dense of reinforced concrete and asphalt structures and empty lands. NDVI has a negative correlation with LST. The findings obtained show that LST data produced from thermal images is an important source in the interpretation of land cover and land use.

Keywords: Remote sensing, Land Surface Temperature, Air Temperature, Çanakkale, Landsat.

\section{Giriş}

Dünya nüfusu hızla artmakta ve doğal kaynaklar da hızla tüketilmekte ve tahrip olmaktadır (Yaylı, H., 2012). Sadece ülkemizde 1927 y1lında 13,5 milyon olan nüfus 2019 yılında 83 milyona ulaşmış ve 2030 yılı seneryolarına göre ise 93 milyon olması beklenmektedir (Aydınlı ve Çiftçi, 2015; URL 1). Bu artışa bağlı olarak yaşadığımız yeryüzünün arazi örtüsünde ve kullanımında büyük değişikler meydana gelmektedir. $\mathrm{Bu}$ değişiklikler düzensiz kentleşme, doğal kaynakların tahribatı ve yok olması şeklinde özetlenebilir. Çanakkale'nin merkez ilçesi için yapılan bir çalışmada 12 yıllık süreç içerisinde tarım alanlarının \%26.94'lük kısmının yerini kent alanlarına bıraktığı görülmektedir. (Özelkan ve ark., 2018). Arazi örtüsü ve kullanımındaki değişimler şekilsel olduğu kadar araziden yayılan 1sı bakımından da farklılıklara ve anomalilere neden olabilmektedir. Çünkü yeryüzünde bulunan tüm cisimler güneş 1Şı̆̆ını farklı oranlarda soğurur ya da yansıtmaktadır (Ayvacı ve ark., 2018). Arazide meydana gelen değişimlerin tümü yüzey albedosunu, emisyonunu ve evatranspirasyonunu değiştirmektedir (Oke, 2002). İdeal atmosfer koşullarında (açık gökyüzü ve hafif rüzgâr) arazi örtüsünde oluşan tahribat ve betonlaşmadan kaynaklı olarak, kent ile kırsal alanlar arasında 5 ${ }^{\circ} \mathrm{C}$ ile $10{ }^{\circ} \mathrm{C}$ 'yi aşan sıcaklık farklılıkları görülmüştür. (Lac ve ark, 2013).

Uzaktan algılama arazi örtüsü ve kullanımındaki mevcut durumu ve değişimleri belirlemek için yaygın olarak kullanılan bir araçtır (Kavzaoğlu ve Çölkesen, 2011). Uydudan uzaktan algılama, yer yüzeyi sıcaklığı (YYS) değerlerinin ve değişimlerinin belirlenmesinde ve etkilerinin araştırılmasında başarıyla kullanılmaktadır (Yomralıoğlu, 2000; Arca, 2012; Liu ve ark., 2014). YYS, arazi örtüsü ve kullanımına göre farklılık gösterir ve arazide meydana gelen değişimlerin belirlenmesinde s1klıkla kullanılır (Bayar ve Karabacak, 2017). Kent 1S1 adas1 (Yüksel ve Yılmaz, 2008), iklim (Özelkan ve ark., 2015), tarım (Özelkan, 2014), kuraklık (Özelkan ve ark, 2011a), ormancılık (Özelkan ve ark., 2011b), denizcilik (Durna, 2014) ve daha pek çok çalışmada YYS verileri önemli ve etkin bir veri kaynağıdır.YYS çalışmaları uydu görüntülerinin termal bantları kullanılarak gerçekleştirilmektedir (Weng, 2009; Hamdi, 2010; Liu ve Zhang., 2011; Zhou ve ark., 2011).
YYS değerinin başarılı bir şekilde hesaplanabilmesi için atmosferik etkilerin değerlerine, sensör parametrelerine, yer yüzeyi yayınırlığı gibi YYS hesaplanmasında yardımcı olacak verilere ihtiyaç duyulmaktadır (Şekertekin ve Bonafani, 2020). YYS hesaplanmasında Tek kanal, Çok açı, Çok kanal, Bölünmüş Pencere yöntemleri kullanılmaktadır (Şekertekin ve ark., 2015). Tek kanal yöntemi, atmosferden yayılan yeryüzündeki ışınım değişimi iki farklı kanalda algılanan veriler ile doğru orantılıdır. $\mathrm{Bu}$ sayede atmosferik etki ve yüzey 1 şınım değerlerine ulaşılabilmektedir (Çelik, B, 2013). Atmosferik sıcaklık, nem, su buharı ve termal uydu görüntüsünden elde edilen parlaklık sıcaklık değerleri kullanılmaktadır (Price,1981; Chedin ve ark., 1985). Çok açı yönteminde farklı iki uydu kullanılır, bunlar kutup ve sabit yörüngeli uydulardır ve farklı iki uyduların eş zamanlı olarak aynı konumdan alınan veriler dâhilinde farklı bakış açısı ile cismin farklı yutulum değeri oluşturması temel alınmıştır (Becker, 1982; Goradetskii, 1985). Çok kanal yönteminde uydudaki iki farklı komşu termal bant temel alınarak cismin farklı yutulum değeri oluşturması temel alınarak oluşturulan yöntemdir (Ho ve ark, 1986). Bölünmüş pencere yönteminde ise çok açı ve çok kanal yöntemlerinin birleştirilmesi sonucunda farklı değer sabitleri ile eşleştirilerek cismin farklı yutulum değeri oluşturmasından yola çıkılarak hesaplanan yöntemdir (Price, 1983; Becker, 1987). Uydudan uzaktan algılama ile geniş alanları görüntüleyebilen termal veri kaynakları ise Landsat (Dağlıyar ve ark., 2015), ASTER (Oğuz, H, 2015), MODIS (Şekertekin ve ark., 2018) ve NOAA (Şahin ve ark., 2011), gibi uydulardır. Yüksek mekânsal çözünürlüklü bir termal algılayıcıya sahip olması Birleşik Devletleri Jeoloji Araştırmaları Kurumu'ndan (USGS) ücretsiz temin edilebilmesi nedeniyle Landsat uydularına ait termal bantlar YYS elde edilmesinde en yaygın kullanılan veri kaynaklarından biridir. $\mathrm{Bu}$ doğrultuda Landsat 5 (Thematic Mapper) TM (Sobrino, J ve ark., 2004), Landsat 7 Enhanced Thematic Mapper Plus (ETM+) (Mallik ve ark., 2008) ve Landsat-8 Operational Land Imager and Thermal Infrared Sensor OLI/TIRS (Rozenstein ve ark., 2014) ile sayısız YYS çalışması gerçekleştirilmiştir.

Çalışmada Çanakkale ilinin 1984 ile 2019 yılları arasındaki her bir yıl için Temmuz ayında temin edilen 66 adet (2002, 2006, 2012, 2017 yılları haricinde) Landsat uydu görüntüsünün termal bantları kullanılarak YYS değişimi incelenmiştir. Bu çalışmada atmosferik su buharı içeriği ve hava sıcaklığı gibi girdi 
parametrelerine ihtiyaç duymadan çalışan Artis \& Carnahan Denklemi ve Tek kanal yöntemlerinden Radyatif Transfer Denklemi, Tek kanal Denklemi, Tek Pencere Denklemi olacak şekilde dört farklı yöntem ile YYS değeri hesaplanmıştır. Dört farklı yöntemle türetilmiş YYS değerleri, 10 farklı meteoroloji istasyonundan temin edilen uydu geçişi ile eş zamanlı saatlik meteorolojik veriler ile kıyaslanmıştır. Çalışmanın aşamaları; 1) YYS değerlerinin farklı yöntemlerle hesaplanması, ve 2) Doğruluk analizi: YYS değerlerinin meteoroloji istasyonlarında uydu geçişi ile eş zamanlı ölçülmüş hava sıcaklığı verileri ile karşılaştırılması ve en başarılı yöntemin korelasyon - regresyon analizi ve kök ortalama karesel hata (RMSE) ile belirlenmesi, ve 3) Fiziki ve çevresel etkenler karşısında YYS değerlerindeki değişimin incelenmesidir. YYS değerini üretmede denklemlerin başarı durumları, arazi örtüsü olarak homojen alanlara sahip meteorolojiistasyonları üzerinde değerlendirilmiştir.

\section{Materyal ve Metot}

\section{1. Çalışma Alanı}

Çalışma alanı, Çanakkale sınırları içinde Avrupa ile Asya'yı kapsayan alanda bulunmaktadır. İl sınırlarının iki kıta üzerinde dağılmış olması ve Çanakkale Boğazı nedeni ile jeopolitik olarak önemli bir alanı kapsamaktadır. İl sınırları 39 $30^{\prime}-40^{\circ}$ $45^{\prime}$ Kuzey enlemleri ve $27^{\circ} 45^{\prime}-25^{\circ} 35^{\prime}$ Doğu boylamları içinde yer alır. Türkiye'nin kuzeybatısında, Marmara Bölgesi'nin güneybatısındadır. Çanakkale'nin kuzeyinde Edirne ile Tekirdağ illeri, doğu ve güneydoğusunda Balıkesir ili bulunmaktadır. Güneydoğu ve güney kısımları yüksek rakımlı bölgeler olmak ile birlikte içerisinde Kaz dağlarının en yüksek rakımlı tepesi 1774 m rakıma sahip Karakaş tepesini barındırmaktadır (URL 2). Çanakkale ilinin iklimi bulunduğu konum nedeniyle Akdeniz ve Karadeniz iklimlerinin geçiş iklimi olarak tanımlanan bölgesel 1lıman Marmara iklimidir (Sensoy ve ark., 2008; Koçman, 1993). Ortalama hava sıcaklığı değeri $14.3{ }^{\circ} \mathrm{C}$ olmakla birlikte yazları $24{ }^{\circ} C^{\prime}$ ye kadar çıkmaktadır. T.C. Tarım ve Orman Bakanlığı Meteoroloji Genel Müdürlüğü (MGM) verilerine göre en sıcak ay Temmuz en soğuk ay Ocak iken en kurak ay $3.3 \mathrm{~mm}$ yağış ile Ağustos ve en yağışlısı ise $105.3 \mathrm{~mm}$ ile Aralık ayıdır (URL 3). 1990 yıllarında 430 bin toplam nüfusun 168 bini kentte yaşamaktayken 2017 yılında 530 bin olan toplam nüfusun 378 bini kent ve ilçelerde yaşar hale gelmiştir (URL 4). Nüfus yoğunluğu il merkezinde yüksek olmakla birlikte sahil kesimlerinde önemli yerleşimler bulunmaktadır (Şekil 1).

\section{1. Çalışma Alanı}

\subsubsection{Uzaktan Algılama Verileri}

Bu çalışma kapsamında Çanakkale ilinin 1984 ile 2019 yılları arasındaki her bir yıl için Temmuz ayında algılanan 66 adet (2002, 2006, 2012, 2017 y1lları haricinde) Landsat-5 TM ve Landsat-8 OLI/TIRS uydu görüntüsü kullanılmıştır. Görüntüler USGS'den temin edilmiştir (https://earthexplorer.usgs.gov).

\subsection{Metot}

$\mathrm{Bu}$ çalışmada atmosferik su buharı içeriği ve hava sıcaklığı gibi girdi parametrelerine ihtiyaç duymadan çalışan Artis \& Carnahan Denklemi ve tek kanal yöntemlerinden Radyatif Transfer Denklemi, Tek kanal Denklemi, Tek Pencere Denklemi olacak şekilde dört farklı yöntem ile YYS değeri hesaplanmıştır. YYS değerlerinin Landsat uydu görüntülerinden hesaplaması ArcGIS 10.5 Model Builder ile gerçekleştirilmiştir. Sekiz farklı
Landsat 5 TM uydu görüntüsünde 120 m mekânsal çözünürlüklü bir adet termal band ve $30 \mathrm{~m}$ mekânsal çözünürlüklü altı adet multispektral bant olmak üzere 7 bandı bulunmaktadır. Landsat 8 OLI/TIRS uydu görüntüsünün $100 \mathrm{~m}$ mekânsal çözünürlüklü 2 termal bandı, $30 \mathrm{~m}$ mekânsal 8 multipspektral bandı ve $15 \mathrm{~m}$ mekânsal çözünürlüklü 1 adet pankromatik bandı olmak üzere 11 bandı bulunmaktadır. Çalışma alanı iki farklı Landsat rota/sıra görüntüsünü içerdiğinden her bir yıldaki 181/32 ve 181/33 rota/sıra görüntüleri mozaikleme ile birleştirilmiştir.

\subsubsection{Meteorolojik Veriler}

Çalışma kapsamında Çanakkale İli sınırları içerisinde bulunan Meteoroloji Genel Müdürlüğü'ne ait 12 meteoroloji istasyonunda temin edilmiş veriler kullanılmıştır. Bu istasyonlar Çanakkale Merkez Meteoroloji İstasyonu (40 $8^{\circ} 30.21^{\prime \prime K}$, $\left.26^{\circ} 24^{\prime} 1.58^{\prime \prime D}\right)$, Çanakkale Havaalanı Meteoroloji İstasyonu (40 $\left.8^{\prime} 16.80 " \mathrm{~K}, \quad 26^{\circ} 25^{\prime} 35.76^{\prime \prime D}\right)$, Eceabat Kabatepe Meteoroloji İstasyonu $\left(40^{\circ} 12^{\prime} 2.79^{\prime \prime} \mathrm{K}, 26^{\circ} 16^{\prime} 17.50^{\prime \prime} \mathrm{D}\right)$, Gelibolu Merkez Meteoroloji İstasyonu $\left(40^{\circ} 24^{\prime} 29.16^{\prime \prime K}, \quad 26^{\circ} 38^{\prime} 30.12^{\prime \prime D}\right)$, Gelibolu Milli Park Meteoroloji İstasyonu (40¹2'29.86"K, 26¹6'54.12"D), Bayramiç Meteoroloji İstasyonu (3948'52.92"K, 26³5'26.16"D), Ayvacik Merkez Meteoroloji İstasyonu (39³6'29.16"K, 26²3'44.88"D), Ayvacık Gürpınar Meteorolojiİstasyonu (39³3'49.24"K, 26 6'0.62"D), Lapseki Merkez Meteorolojiİstasyonu (40²0'23.98"K, 2641'47.04"D), Çan Merkez Meteorolojiİstasyon (40 $0^{\circ} 57.94 " \mathrm{~K}, 27^{\circ}$ 3'23.04"D), Biga Meteorolojiİstasyonu (40²13'59.28"K, $\left.27^{\circ} 15^{\prime} 48.96 " \mathrm{D}\right)$, Ezine Meteoroloji İstasyonu (3946'25.99"K, $\left.26^{\circ} 20^{\prime} 44.16 " \mathrm{D}\right)$ 'larıdır (Şekil 1). Meteoroloji Genel Müdürlüğünden temin edilen $2 \mathrm{~m}$ seviyesindeki hava sıcaklığ 1 değerleri, kullanılan 12 meteoroloji istasyonlarının çalışma sürelerinin belirli zaman dilimlerinde olmasından dolayı çalışılan her yıl için temin edilememiştir. Meteoroloji istasyonları ve çalışma süreleri tablo 4'de gösterilmektedir. Ayrıca Meteoroloji Genel Müdürlügüunden $2 \mathrm{~m}$ hava sıcaklığ̀ temin edilmesine rağmen bazı istasyonlarda (Biga, Çan, Ayvacık) bulut örtüsünden kaynaklı olarak her yıl için YYS verileri sağlanamamıştır. Uydu görüntüleri ile eş zamanlı $2 \mathrm{~m}$ seviyesinde ölçülen hava sıcaklığı değerleri, atmosferik etkenler (yükselen 1şınım değeri, alçalan 1şınım değeri, atmosferik geçirgenlik değerleri) temin edilmiştir. Atmosferik etkenler Atmosferik Parametre Hesaplayıcısı tarafindan konum verileri ve uydu görüntüsü zamanı girdileri ile elde edilmiştir. Çanakkale bölgesindeki 12 istasyonun atmosferik etkenleri bulunmuş ve her sıra/rot için atmosferik etkenlerin ortalamaları alınarak hesaplamalar yapılmıştır. $\mathrm{Bu}$ sıcaklık verileri ortalama atmosferik hava sıcaklığı değeri hesaplanmasında ardından Tek Pencere denklemi ile YYS elde edilmesinde kullanılmıştır. Atmosferik geçirgenlik, yükselen 1şınım ve alçalan 1 şınım değerleri Radyatif Transfer Denklemi ve Tek Kanal Denklemi ile YYS değeri elde edilmesinde kullanılmıştır. YYS denklemleri ile hava sıcaklığı değerleri arasındaki ilişsinin incelenmesi için kullanılmıştır.

filtre boyutunun denendiği çalışmada, $5 \times 5$ boyutlu ortalama filtre uygulanmış YYS değerlerinin iklim verileri ile

İlişkilendirilmesinin daha uygun olduğu Özelkan ve ark. (2015) tarafindan önerilmiştir. $\mathrm{Bu}$ nedenle, YYS değerleri hesaplandıktan sonra ArcMap üzerinden her bir görüntüye $5 \times 5$ 'lik ortalama filtre uygulanmıştır. $\mathrm{Bu}$ çalışmada YYS üretiminde takip edilen iş akış diyagramı şekil 2'de verilmiştir. YYS değerleri meteoroloji genel müdürlüğünden eş zamanlı 
alınan $2 \mathrm{~m}$ hava sıcaklığı değerleri ile karşılaştırılmış ve korelasyon - regresyon analizi ve RMSE değerleri ile doğrulukları hesaplanmıştır. Elde edilen sonuçların arazi örtüsü ve kullanımı ile ilişkisi multispektral ve NDVI görüntüleri ile yorumlanmıştır.

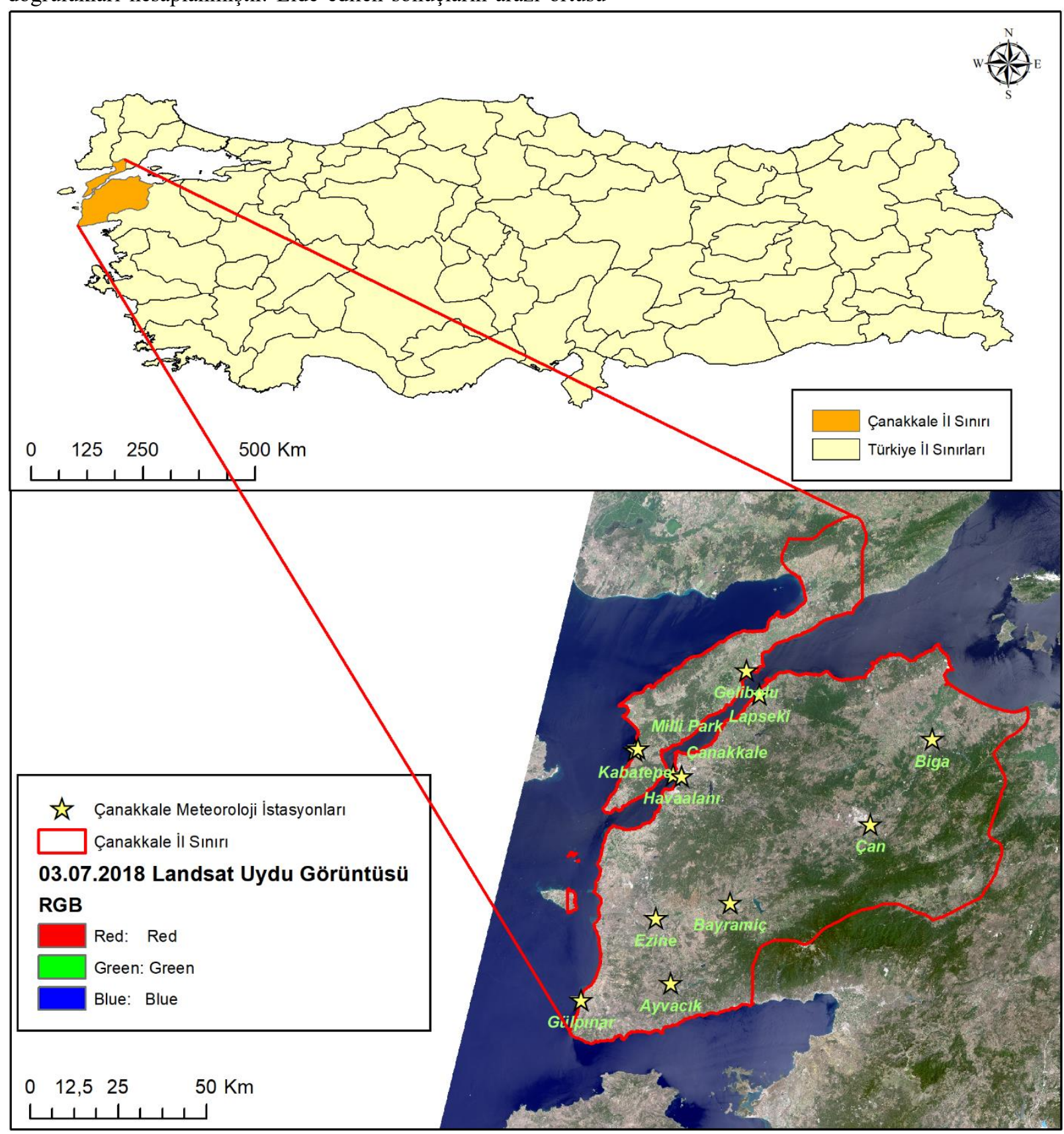

Şekil 1.Çanakkale Lokasyon Haritası (Türkiye Haritası Görüntüsü Google Earth Pro’dan elde edilmiştir.)

\subsubsection{YYS verilerinin Hesaplanmast}

Landsat serisi uydu verilerinden YYS verilerini türetme adımları sırasıyla aşağıdaki gibidir.

1) Sayısal verilerin (DNs) radyans değerine $\left(\mathrm{Wm}^{-2} \mathrm{sr}^{-1} \mu \mathrm{m}^{-}\right.$ 1) dönüştürülmesi,

5) Yer yüzeyi yayınırlığı değerinin (ع) hesaplanması,

6)Ortalama atmosferik hava sıcaklığının $\left(\mathrm{T}_{\mathrm{a}}\right)$ hesaplanmas1,
2) Radyans değerlerinin parlaklık sıcaklığı değerlerine dönüştürülmesi,

3) Normalize edilmiş fark bitki indisinin (NDVI) oluşturulması,

4) Bitki örtüsü oranının $\left(\mathrm{P}_{\mathrm{v}}\right)$ belirlenmesi,

7) YYS hesaplanması. 


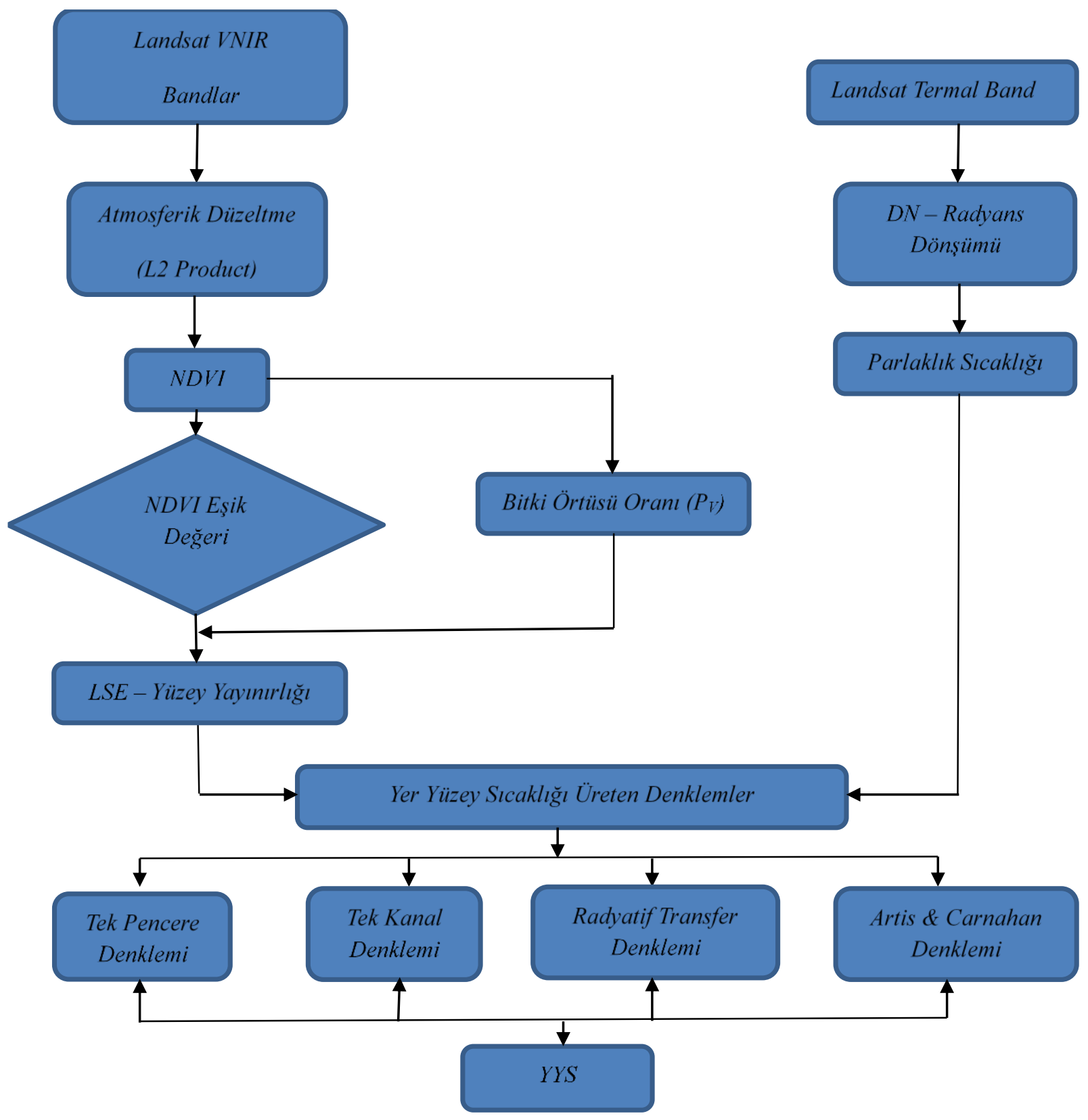

Şekil 2.Artis\&Carnahan, Tek Pencere, Tek Kanal, Radyatif Transfer Denklemi yöntemleri ile YYS üretimine ait iş akış diyagramı

\subsubsection{Sayısal Veri Değerinin (DNs) Radyans Değerine $\left(W^{-2} s r^{-1} \mu m^{-1}\right)$ Dönüştür rülmesi}

Landsat-8 OLI/TIRS uydusu verileri için (USGS, 2016);

$L_{\lambda}=M_{L} \times Q_{C A L}+A_{L}$

$L_{\lambda}=$ Radyans değeri $(\mathrm{Wm}-2 \mathrm{sr}-1 \mu \mathrm{m}-1), M_{L}=$ Banda özel radyans çarpan ölçekleme faktörü, $Q_{C A L}=$ incelenen pikselin sayısal değerini (DN), $A_{L}=$ banda özel radyans katkı ölçekleme faktörü değerini ifade etmektedir.

Landsat-5 TM uydusu verileri için (Chander ve ark., 2009);

$L_{\lambda}=\left[\frac{L M A X_{\lambda}-L M I N_{\lambda}}{Q C A L M A X-Q C A L M I N}\right] \times\left[Q_{C A L}-Q C A L_{M I N}\right]+L M I N_{\lambda}$

$L_{\lambda}=$ Sensördaki spektral radyans $\left(\mathrm{Wm}^{-2} \mathrm{sr}^{-1} \mu \mathrm{m}^{-1}\right), L M A X_{\lambda}=$ $Q C A L_{M A X}$ 'a göre ölçeklendirilen sensördeki spektral radyans $\left(\mathrm{Wm}^{-2} \mathrm{sr}^{-1} \mu \mathrm{m}^{-1}\right), \quad L M I N_{\lambda}=Q C A L_{M I N}$ 'a göre ölçeklendirilen sensördeki spektral radyans $\left(\mathrm{Wm}^{-2} \mathrm{sr}^{-1} \mu \mathrm{m}^{-1}\right), Q_{C A L}=$ Sayısal veri değeri, $Q C A L_{M A X}=L M A X_{\lambda}(\mathrm{DN})$ 'ya karşılık gelen maksimum nicelleştirilmiş kalibre edilmiş sayısal veri değeridir, $Q C A L_{M I N}=$ $\operatorname{LMIN}_{\lambda}(\mathrm{DN})$ 'ya karşılık gelen ninimum nicelleştirilmiş kalibre edilmiş sayısal veri değeridir.

\subsubsection{Radyans Değerinin Parlaklık Sicaklık (Brightness temperature) Değerine Dönüştürülmesi}

Landsat-5 TM uydusu için 6. Landsat-8 OLI/TIRS uydusu için 10. bantlara dönüşüm denklemi uygulanmaktadır (USGS, 2016; Chander ve ark., 2009).

$$
T=\frac{K_{2}}{\ln \left(\frac{K_{1}}{L_{\lambda}}+1\right)}
$$

$\mathrm{T}=$ Kelvin cinsinden parlaklık sicaklığ $1(\mathrm{~K}), \quad \mathrm{K}_{1}=$ Birinci Kalibrasyon Sabiti, $\mathrm{K}_{2}=$ İkinci Kalibrasyon Sabiti, 
$\mathrm{L} \lambda=$ Sensördeki spektral radyansdır $\left(\mathrm{Wm}^{-2} \mathrm{sr}^{-1} \mu \mathrm{m}^{-1}\right)$. Kalibrasyon sabitlerine tablo 3'den erişilebilir.

\subsubsection{Normalize Edilmiş Fark Bitki İndisi (NDVI)}

Kırmızı ve yakın kızılötesi bantlarının yansıtım değerlerinden yararlanarak hesaplanan NDVI indeksi -1 ile +1 arasında değer alır (Rouse ve ark., 1973). Bitki örtüsü oranı (Pv) ve yüzey yayınırlığı (emissivity: $\varepsilon$ ) değerlerinin belirlenebilmesi için gerekli olan NDVI ile arazi örtüsü türleri, özellikle bitki örtüsü durumu belirlenir (Salih ve ark., 2018; Akyürek, 2020).

$N D V I=\frac{\rho N I R-\rho R E D}{\rho N I R+\rho R E D}$

Denklemde NDVI; Normalize edilmiş bitki örtüsü indisi, $\rho_{N I R}$; yakın kızılötesi bant yansıtımını ve $\rho_{R E D}$; kırmızı bant yansitımını ifade etmektedir (4).

\subsubsection{Bitki Örtüsü Oranının Belirlenmesi (Proportional vegetation: $P v$ )}

Carlson ve Ripley (1997) tarafından geliştirilen bitki örtüsü oranı $\left(P_{v}\right)$, yer yüzey yayınırlığı hesabı için gerekli bir parametredir. NDVI değeri ile birlikte NDVI maksimum $\left(N D V I_{\max } \mathrm{e}\right.$ NDVI minumum $\left(N D V I_{\min }\right.$ değerleri kullanılarak hesaplanmaktadır. $N D V I_{\max } N D V I_{\min }$ histogram üzerinden elde edilen değerlerin yerine sirasiyla 0.5 ve 0.2 olarak alınabilmektedir (Sobrino ve ark., 2004). Denklem eşitliği (5) deki gibi gösterilmektedir.

$P_{v}=\left[\frac{N D V I-N D V I_{\min }}{N D V I_{\operatorname{mak}}-N D V I_{\min }}\right]^{2}$

\subsubsection{Yer Yüzeyi Yayınırlığı (LSE: Land Surface Emissivity(E)) Hesabı}

LSE, YYS değerinin hesaplanabilmesi için gerekli olan bir parameteredir. LSE, uzun dalga radyasyon spektrumunda bir yüzeyin 1 şınım ve soğurma yeteneğinin bir ölçüsüdür (Sobrino ve ark., 2008). LSE, büyük ölçüde inceleme alanının arazi örtüsünün özelliğine (bitki örtüsü, toprak türü ve pürüzlülük vb) bağlıdır (Stathopoulou ve Cartalis, 2007; Salih ve ark., 2018).

$0.2 \leq \mathrm{NDVI} \leq 0.5$ ise;

$\varepsilon=\varepsilon_{v} P_{v}+\varepsilon_{s}\left(1-P_{v}\right)+d \varepsilon$

Yukarıdaki eşitlikte $\varepsilon v$ bitki örtüsü için yer yüzeyi yayınırlığ değerini, $\varepsilon s$ toprak için yer yüzeyi yayınırlığ değerini ve $\mathrm{d} \varepsilon$ ise doğal yüzeylerin geometrisinden kaynaklanan etkileri göstermektedir. Pv ise bitki oranı ifade etmektedir.

$\varepsilon=m P_{v}+n$

$m=\varepsilon_{v}-\varepsilon_{s}-\left(1-\varepsilon_{s}\right) F_{\varepsilon v}$

$n=\varepsilon_{s}+\left(1-\varepsilon_{s}\right) F_{\varepsilon v}$

$\mathrm{Bu}$ veriler dahilinde yer yüzey yayınırlığı 0.2 ile 0.5 aralığında son formül olarak denklem (10) olarak ifade edilmektedir.

$\varepsilon=0.004 P_{v}+0.986$
Tablo 1. NDVI ile Yer yüzey yayınırlığı ilişkisi (Sobrino, 2008)

\begin{tabular}{|l|c|c|}
\hline \multicolumn{1}{|c|}{ Numara } & NDVI & $\begin{array}{c}\text { Yer Yüzeyi Yayınırlı̆̆ } \\
(\boldsymbol{\varepsilon})\end{array}$ \\
\hline 1 & $N D V I<0.2$ & $0.979-0,035 \times p R E D$ \\
\hline 2 & $0.5>N D V I>0.2$ & $0.004 \times P_{v}+0.986$ \\
\hline 3 & $N D V I>0.5$ & 0.99 \\
\hline
\end{tabular}

\subsubsection{Ortalama Atmosferik Sicaklık Hesabı $\left(T_{a}\right)$}

Ülkemiz coğrafi olarak orta enlem kuşağında yer almaktadır. $\mathrm{Bu}$ nedenle ortalama atmosferik sıcaklık değeri hesaplamasında orta enlem kuşağında ve YYS değerlendirmelerin hangi mevsimde olduğu dikkate alınarak hesaplama yapılmaktadır (Qin ve ark., 2001) (Tablo 2).

Tablo 2. Bölgelere göre Ortalama Atmosferik $\left(T_{a}\right)$ Sicaklık ilişkisi (Qin ve ark., 2001)

\begin{tabular}{|l|c|}
\hline \multicolumn{1}{|c|}{ Bölge } & $\begin{array}{c}\text { Ortalama Atmosferik } \\
\text { Sicaklık }\left(\boldsymbol{T}_{\boldsymbol{a}}\right)\end{array}$ \\
\hline $\begin{array}{l}\text { USA (Amerika Birleşik } \\
\text { Devletleri) }\end{array}$ & $25,9396+0,88045 \times T_{0}$ \\
\hline Tropikal & $17,9769+0,91715 \times T_{0}$ \\
\hline Orta-Meridyen Yaz & $16,0110+0,92621 \times T_{0}$ \\
\hline Orta-Meridyen Klş & $19,2704+0,91118 \times T_{0}$ \\
\hline
\end{tabular}

\subsubsection{Yer Yüzey Sicaklı̆̆ (YYS) Hesabı}

YYS hesabı için geliştirilen farklı denklemlerin gerçek yer sıcaklığı değerini belirlemedeki başarımı dört farklı yöntem ile değerlendirilmiştir.

\subsection{Tek Pencere (The Qin et al.'s mono-window algorithm) Denklemi ile YYS Hesabt}

Tek pencere denklemi (11) Qin ve ark, (2001) tarafindan Landsat TM termal verileri (TM6) için geliştirmişlerdir. Bu metota ait üç ana parametre; yüzey yayınırlığı (land surface emissivity), atmosferik geçirgenlik (atmospheric transmittance) ve ortalama atmosferik sicaklık (mean atmospheric temperature) değeridir.

$T_{S}=\frac{\left\{a(1-C-D)+[b(1-C-D)+C+D] T-D \cdot T_{a}\right\}}{C}$

Tek pencere denkleminde a ve $b$ denklem sabiti olup sırasılyla $-67,355351$ ve 0,458606'ye eşittir. C ve D parametreleri (12), (13) ise yer yüzeyi yayınırlı̆̆ (land surface

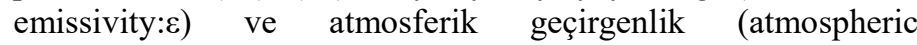
transmittance: $\tau$ ) değerlerinden türetilen bileşenlerdir. Formülde Ts; Kelvin (K) cinsinden yer yüzey sıcaklığını, T; Kelvin (K) cinsinden parlaklık sicaklık değerini, $T_{a}(14)$; ortalama atmosferik sıcaklık değerini temsil etmektedir. Çalışmada ortameridyen yaz bölgesi ele alınmıştır (Tablo 2).

$$
\begin{aligned}
& C=\varepsilon \times \tau \\
& D=(1-\tau)[1+(1-\varepsilon) \times \tau] \\
& T_{a}=16.0110+0.92621 \times T_{0}
\end{aligned}
$$


Burada $T_{0}$ :Yüzeye yakın hava sıcaklığı)

\subsection{Tek Pencere (The Qin et al.'s mono-window algorithm) Denklemi ile YYS Hesabt}

Jiménez-Muñoz ve Sobrino (2003) tarafindan tek bir termal kanalın kullanılarak YYS değerinin türetilebildiği tek kanal denklemini geliştirilmiştir.

$\left.T_{-} s=\gamma\left[\left(\psi_{1} \times L_{\text {sen }}\right)+\psi_{2}\right) / \varepsilon+\psi_{3}\right]+\delta$

Bu denklemde Ts; yer yüzey sıcaklığı değerini (K), Lsen; algılayıcıdaki ışınım (Wm-2 sr-1 $\mathrm{Wm}-1)$ değeri, $\psi_{-} 1, \psi_{-} 2, \psi_{-} 3$ atmosferik fonksiyonlar, $\gamma, \delta$ iki parametredir (Şekertekin ve Bonafoni, 2020).

$\gamma \approx \frac{T^{2}}{b_{\gamma} L_{s e n}}$

$\delta \approx T-\frac{T^{2}}{b_{\gamma}}$

T; Parlaklık sıcaklığı değerini, by; değeri Landsat 5 ve Landsat 8 için 1256 ve 1320 değerlerini almaktadır. Atmosferik fonsiyoneller denklemlerde $(18,19,20)$ gösterilmektedir.

$\psi_{1}=\frac{1}{\tau}$

$\psi_{2}=-L_{\lambda}{ }^{\downarrow}-\frac{L_{\lambda}{ }^{\uparrow}}{\tau}$

$\psi_{3}=L_{\lambda}{ }^{\downarrow}$

Burada $L_{\lambda}{ }^{\downarrow}$ alçalan 1 şınım değeri $\left(\mathrm{W} \cdot \mathrm{m}^{-2} \cdot \mathrm{sr}^{-1} \cdot \mu \mathrm{m}^{-1}\right), \quad L_{\lambda}{ }^{\uparrow}$ yükselen 1 şınım değeri $\left(\mathrm{W} \cdot \mathrm{m}^{-2} \cdot \mathrm{sr}^{-1} \cdot \mu \mathrm{m}^{-1}\right), \quad \tau$ atmosferik geçirgenliktir.

\subsection{Radyatif Transfer (Radiative Equation Method) Denklemine ile YYS Hesabt}

Transfer

$$
L_{\lambda}{ }^{\text {sen }}=\left[\varepsilon B_{\lambda}\left(T_{s}\right)+(1-\varepsilon) L_{\lambda}{ }^{\downarrow}\right] \tau+L_{\lambda}{ }^{\uparrow}
$$

Formülü içerisinde kara cisim sıcaklık değeri (B $\lambda(\mathrm{Ts})$ : blackbody radiance) barındırmaktadır. Kara cisim sicaklık değerine ulaşılması için denklem ters çevrilmektedir. Bu şekilde denklem (22) haline gelmektedir (Jiménez-Muñoz ve ark, 2008).

$B_{\lambda}\left(T_{S}\right)=\frac{L_{\lambda}{ }^{s e n}-L_{\lambda}{ }^{\uparrow}-\tau(1-\varepsilon) L_{\lambda}{ }^{\downarrow}}{\tau \times \varepsilon}$

Lsen $\lambda$, sensördeki 1şınım değeri (Top of Atmospheric (TOA) radiance) $L_{\lambda}^{\uparrow}$, yükselen 1 şınım değeri (upwelling atmospheric radiance) $L_{\lambda}^{\downarrow} \downarrow$, alçalan 1şınım değeri (downwelling atmospheric radiance), $\varepsilon$,yer yüzey yayınırlı̆̆ emissivity), $\tau$, atmosferik geçirgenliktir (total atmospheric transmissivity)

$$
T_{S}=\frac{K_{2}}{\ln \left(\frac{K_{1}}{B_{\lambda}\left(T_{S}\right)}+1\right)}
$$

Ts: Yer yüzey sıcaklık değerini vermektedir. K2 ve K1

\begin{tabular}{|c|c|c|}
\hline UYDU & $\begin{array}{c}\mathbf{K}_{1} \\
\left(\text { Watts } /\left(\mathbf{m}^{2} \cdot \text { srad} \cdot \mu \mathrm{m}\right)\right)\end{array}$ & $\mathrm{K}_{2}$ (Kelvin) \\
\hline $\begin{array}{c}\text { Landsat } 5 \\
\text { (Bant 6) }\end{array}$ & 607.76 & 1260.56 \\
\hline $\begin{array}{l}\text { Landsat } 8 \\
\text { (Band } 10\end{array}$ & 774.89 & 1321.08 \\
\hline
\end{tabular}
kalibrasyon sabitleridir (Tablo 3).

\subsection{Artis \& Carnahan Denklemi ile YYS Hesabt}

Artis ve Carnahan (1982) tarafından kentsel alanlardaki konut çatılarındaki termogramların termal uydu görüntülerinden tespiti hedeflenmiştir. Yüzey yayınırlı̆̆ 1 , termal bant ve karacisim ışıma sabiti alınarak hesaplanır.

$$
T_{S}=\frac{T_{b}}{T_{b} \times \frac{\lambda}{a} \times \ln (\varepsilon)+1}
$$

Burada, Ts $=$ Yer yüzey sıcaklığı değeri kelvin cinsinden, $\mathrm{Tb}=$ Parlalık sıcaklığı kelvin $(\mathrm{K})$ cinsinden, $\varepsilon=$ yüzey yayınırlığı, $\mathrm{a}=\mathrm{hc} / \mathrm{K}(1.438 \times 10-2 \mathrm{mK}), \mathrm{h}=$ Planck sabiti $(6,26 \times 10-34 \mathrm{~J} / \mathrm{s}), \mathrm{c}=$ 1şık hızı $(2,998 \times 108 \mathrm{~m} / \mathrm{s}) \mathrm{K}=$ Boltzman sabiti $(1,38 \times 10-23 \mathrm{~J} / \mathrm{K})$, $\lambda=$ Landsat 5 ve Landsat 8 için $11,45 \mu \mathrm{m}, 10,895 \mu \mathrm{m}$ değerlerini almaktadır.

\subsection{Doğruluk Analizi}

Çalışmadaki YYS değerleri 12 farklı meteoroloji istasyonundan temin edilen eş zamanlı saatlik veriler ile kıyaslanmıştır. Oluşturulan YYS değerlerinin doğruluğunu belirlemek için meteoroloji istasyonlarının eş zamanlı hava sıcaklık verileri ile karşılaştırılması ve en başarılı olan denklem regresyon - korelasyon analizi ve kök ortalama karesel hata (RMSE) değerleri ile belirlenmiştir.

\section{Araştırma Sonuçları ve Tartışma}

$\mathrm{Bu}$ çalışmada termal verilerden elde edilen YYS değerleri ile meteoroloji istasyonlarından elde edilen hava sıcaklığı değerleri ilişkilendirilmiştir. Termal uydu görüntülerinden farklı yöntemlerle elde edilen YYS değerlerinin alansal dağılımları ile birlikte bölgedeki bitki örtüsünü ortaya koyan NDVI indisin alansal dağılımları şekil 3'te, YYS değerlerinin zamansal değişimi şekil 4'te gösterilmiştir. Zamansal alansal dağılım haritalarından istasyonların bulunduğu alanların $5 \times 5$ piksel matrisi ile elde edilen farklı yöntemlere ait YYS değerleri ile bu istasyonlarda uydu geçişi ile eş zamanlı olarak meteoroloji istasyonlarında ölçülmüş hava sıcaklığı değerleri arasındakiler ilişki tablo 4'te özetlenmiştir. Çalışmanın bulguları şu şekilde özetlenebilir; homojen arazi örtüsünde bulunan meteoroloji istasyonları yüksek doğruluk ilişkisi göstermiştir. Çünkü heterojen arazi örtüsündeki yaklaşık 2 m'den hava sıcaklığı ölçümlerini gerçekleştiren yerel meteoroloji istasyonları, kentleşmeden kaynaklanan yüzey albedosu, evatranspasyon ve hâkim yerel rüzgârlardan etkilenmektedir. $\mathrm{Bu}$ değişimlerden kaynaklı homojen alanlarda bulunan meteoroloji istasyonları heterojen alanlarda bulunan meteoroloji istasyonlarına göre YYS-Hava Sicaklığı daha anlamlı sonuçlar oluşturmaktadır. Bölüm 3.1 ve Bölüm 3.2. 'de çalışmanın araştırma sonuçları ve bunlarla ilgili tartışmalar ayrıntılı şekilde ortaya konmuştur. 


\subsection{YYS-Meteoroloji İstasyonlarından Ölçülen Hava Sıcaklığı İliş̧kisi}

Yöntemlerin başarı sıralaması RMSE'nin minimum $\left(\mathrm{RMSE}_{\mathrm{min}}\right.$ ), maksimum (RMSE $\mathrm{Rak}_{\text {ak }}$ ) ve ortalama (RMSE ${ }_{\text {ort }}$ ) değerleri dikkate alınarak Artis \& Carnahan Denklemi $\left(\mathrm{RMSE}_{\min }=0.83^{\circ} \mathrm{C}, \mathrm{RMSE}_{\mathrm{mak}}=12.63^{\circ} \mathrm{C}\right.$ ve $\left.\mathrm{RMSE}_{\text {ort }}=5.22^{\circ} \mathrm{C}\right)>$ Tek Pencere Denklemi $\left(\mathrm{RMSE}_{\min }=1.97^{\circ} \mathrm{C}, \mathrm{RMSE}_{\operatorname{mak}}=16.76^{\circ} \mathrm{C}\right.$ ve $\left.\mathrm{RMSE}_{\text {ort }}=8.16^{\circ} \mathrm{C}\right)>$ Tek Kanal Denklemi $\left(\mathrm{RMSE}_{\min }=3.35^{\circ} \mathrm{C}\right.$, $\mathrm{RMSE}_{\operatorname{mak}}=17.67^{\circ} \mathrm{C}$ ve $\left.\mathrm{RMSE}_{\text {ort }}=9.61^{\circ} \mathrm{C}\right)>$ Radyatif Transfer Denklemi $\quad\left(\mathrm{RMSE}_{\min }=3.83^{\circ} \mathrm{C}, \quad \mathrm{RMSE}_{\operatorname{mak}}=18.22^{\circ} \mathrm{C}\right.$ ve $\left.\mathrm{RMSE}_{\text {ort }}=10.08{ }^{\circ} \mathrm{C}\right)$ şeklindedir. Benzer şekilde regresyon korelasyon katsayısı $\left(\mathrm{R}^{2}\right)$ değerleri dikkate alınarak yöntemlerin başarı sıralaması Tek Kanal Denklemi $\left(\mathrm{R}^{2}{ }_{\min }=0, \mathrm{R}^{2}{ }_{\max }=0,98\right.$ ve $\left.\mathrm{R}^{2}{ }_{\text {ort }}=0.67\right)>$ Radyatif Transfer Denklemi $\quad\left(\mathrm{R}_{\min }^{2}=0.01\right.$, $\mathrm{R}^{2}{ }_{\max }=0.98$ ve $\left.\mathrm{R}_{\text {ort }}{ }^{2}=0.65\right)>$ Artis \& Carnahan Denklemi $\left(R^{2}{ }_{\text {min }}=0.04, R^{2}{ }_{\text {max }}=0.96\right.$ ve $\left.R^{2}{ }_{\text {ort }}=0.62\right)>$ Tek Pencere Denklemi $\left(\mathrm{R}_{\text {min }}^{2}=0.01, \mathrm{R}_{\text {max }}^{2}=0.98\right.$ ve $\left.\mathrm{R}_{\text {ort }}^{2}=0.59\right)$ şeklindedir. Artis \& Carnahan Denkleminin anlamlı ilişki oluşturduğu istasyonlar sırasıyla Ayvacık, Bayramiç ve Gelibolu, Tek Kanal Denklemi ve Radyatif Transfer Denkleminin anlamlı değerlerinin olduğu istasyonlar Ayvacık, Bayramiç, Kabatepe, Çan ve Gelibolu'dur (Şekil 4, Şekil 5, Şekil 7). Tek Pencere Denkleminin anlamlı ilişki oluşturduğu istasyonlar ise Ayvacık'tır (Şekil 6). Tüm denklemlerin yüksek korelasyon gösterdiği istasyon Ayvacık ve Çan'dır. Benzer şekilde Bayramiç istasyonunda da Tek Pencere Denklemi dışında yüksek korelasyonlar görülür. Çanakkale kent merkezi örnek sayısının çok, korelasyonun düşük olduğu ancak YYS'nin kentler üzerindeki etkisinin değerlendirilmesinde yüksek kentleşmeyi temsil etmesi bakımından da önemli bir istasyondur. YYS ile yersel sicaklık değerlerinin anlamlı ilişkisinin belirlendiği Ayvacık ve Bayramiç istasyonu ile birlikte yüksek kentleşmeyi temsil eden Çanakkale Merkez istasyonu, aynı zamanda da yöntemlerin başarısını değerlendirme istasyonlarıdır (Şekil 4).

RMSE değerlerine göre değerlendiriliğinde Ayvacık, Bayramiç ve Çanakkale/Merkez istasyonu verilerine göre en başarılı yöntem Artis \& Carnahan Denklemi $\left(\mathrm{RMSE}_{\min }=8.01{ }^{\circ} \mathrm{C}\right.$, $\left.\mathrm{RMSE}_{\min }=2.85^{\circ} \mathrm{C}, \mathrm{RMSE}_{\min }=4.61{ }^{\circ} \mathrm{C}\right)$ 'dır. Yüksek kentleşmenin olduğu bölgelerde, arazi kullanımındaki heterojenlik (çatı çeşitliliği, asfalt yol, beton kaldırım, bahçe, sahil şeridi, deniz, akarsu), doğal olmayan yüzey bileşenleri ve birim alandaki arazi öğelerindeki yoğunluluk tüm yöntemlerin başarısını düşürmektedir. Kentleşmenin yoğun olduğu bölgelerde 1sı adası etkisi, kent alanlarındaki bina çatısı, asfalt yol gibi bileşenlerin 1sıyı soğurma kapasiteleri ve diğer doğal ortamlara göre yüzey sıcaklıklarının farklı olması, YYS-yersel sıcaklık ilişkisinin kurulmasını engeller. Ayvacık ve Bayramiç istasyonlarındaki sıcaklık verileri ile YYS değerleri arasındaki yüksek ilişki gözlenmesinin nedeni, meteorolojik istasyonların kent dışında kurulmuş doğal ve homojen bir arazi örtüsüne sahip olmasıdır.

Uyduların termal bandlarından üretilen YYS ile herhangi bir bölgede görülen yersel atmosferik sıcaklığın ilişsisi değerlendirilmek istendiğinde kent 1sı adası etkisi ve bileşenlerin farklı 1sı depolama kapasitelerinin oluşturduğu etki nedeni ile kent alanlarında kullanılmamalıdır. Kent içindeki meteoroloji istasyonları o bölgedeki hava sıcaklığını yansıtırken, cisimlerin yüzeyindeki sıcaklığı yansıtmaz. Uydudan bir bölgedeki atmosferik yersel sıcaklığın değerlendirmesinde homojenliğin olduğu doğal alanlar tercih edilmelidir. Aynı şekilde YYS ile atmosferik sıcaklığın karşılaştırılmasında kent içindeki meteoroloji istasyonu verilerinden daha ziyade kent alanının dışında homojen arazi örtüsünün bulunduğu doğal alanlarda kurulmuş meteroloji istasyonu verileri kullanılmalıdır. Kentlerdeki 1Sı adası çalışmalarında YYS ile gerçek yüzey sıcaklığının belirlenmesinde kontrol verisi olarak, çatı, asfalt yol yüzeyinden doğrudan ölçülen veriler kullanılmalıdır.

Bunun yanında homojenliğin olduğu kent dışındaki doğal alanlarda bulunan meteoroloji istasyonu bölgelerinde, uydudan belirlenen YYS sıcaklık değerlerinin yersel ölçülen atmosferik sıcaklık değerlerinden saptığı görülmüştür. Ayvacık'ta Artis \& Carnahan Denklemi $7-9{ }^{\circ} \mathrm{C}$, Tek Kanal Denkleminde 11 - 16 ${ }^{\circ} \mathrm{C}$, Radyatif Transfer Denkleminde $12-16{ }^{\circ} \mathrm{C}$, Tek Pencere Denklemi ise $11-14{ }^{\circ} \mathrm{C}$ arasında sapmalar olmuştur. Bayramiç’te YYS denklemlerinin sırasıyla sapma değer aralıkları Artis \& Carnahan Denklemi $2-4{ }^{\circ} \mathrm{C}$, Tek Kanal Denklemi 6 - $8{ }^{\circ} \mathrm{C}$, Radyatif Transfer Denklemi 7 - $9{ }^{\circ} \mathrm{C}$, Tek Pencere Denklemi $5-7{ }^{\circ} \mathrm{C}^{\prime}$ dir. Gelibolu'da ise sapma değer aralı̆̆ı sırasıyla Artis \& Carnahan Denklemi $1-6^{\circ} \mathrm{C}$, Tek Kanal Denklemi $4-8{ }^{\circ} \mathrm{C}$, Radyatif Transfer Denklemi 5 - $9{ }^{\circ} \mathrm{C}$, Tek Pencere Denklemi $2-13^{\circ} \mathrm{C}$ 'dir. 


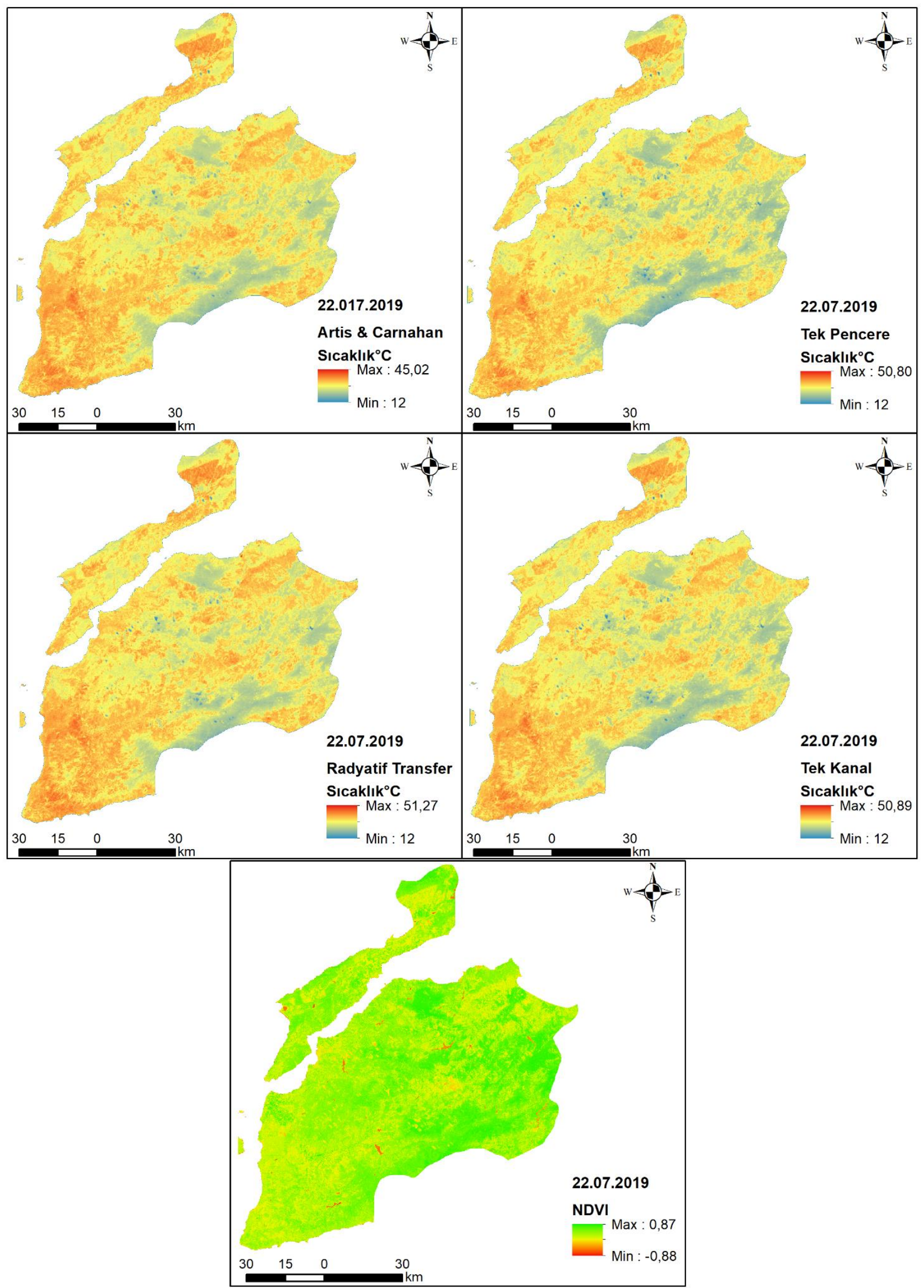

Şekil 3. Mono Pencere, Tek Kanal, Radyatif Transfer Denklemi ve Artis \& Carnahan Denklemleri ile oluşturulan YYS görüntüleri (22.07.2019 tarihli Landsat uydu görüntüsü ile elde edilmiştir.) 
European Journal of Science and Technology

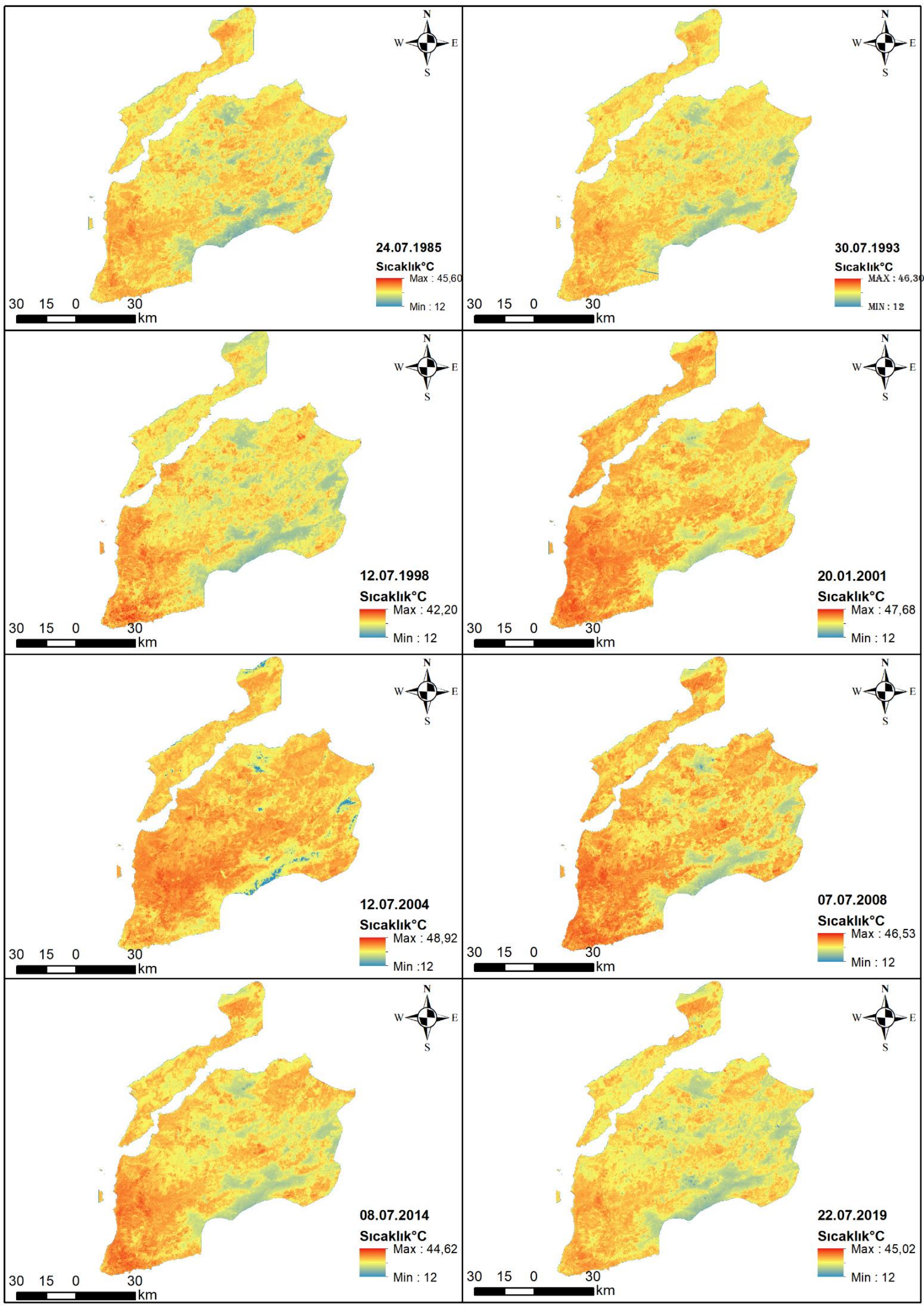

Şekil 4. Artis \& Carnahan Denklemi ile 1985 ile 2018 yılları arasındaki YYS görüntüleri 
Avrupa Bilim ve Teknoloji Dergisi

Tablo 4. YYS denklemlerinin Meteoroloji istasyonları ile R2 ve RMSE dĕgerlerinin gösterimi (* yöntem karşılaştırma istasyonu)

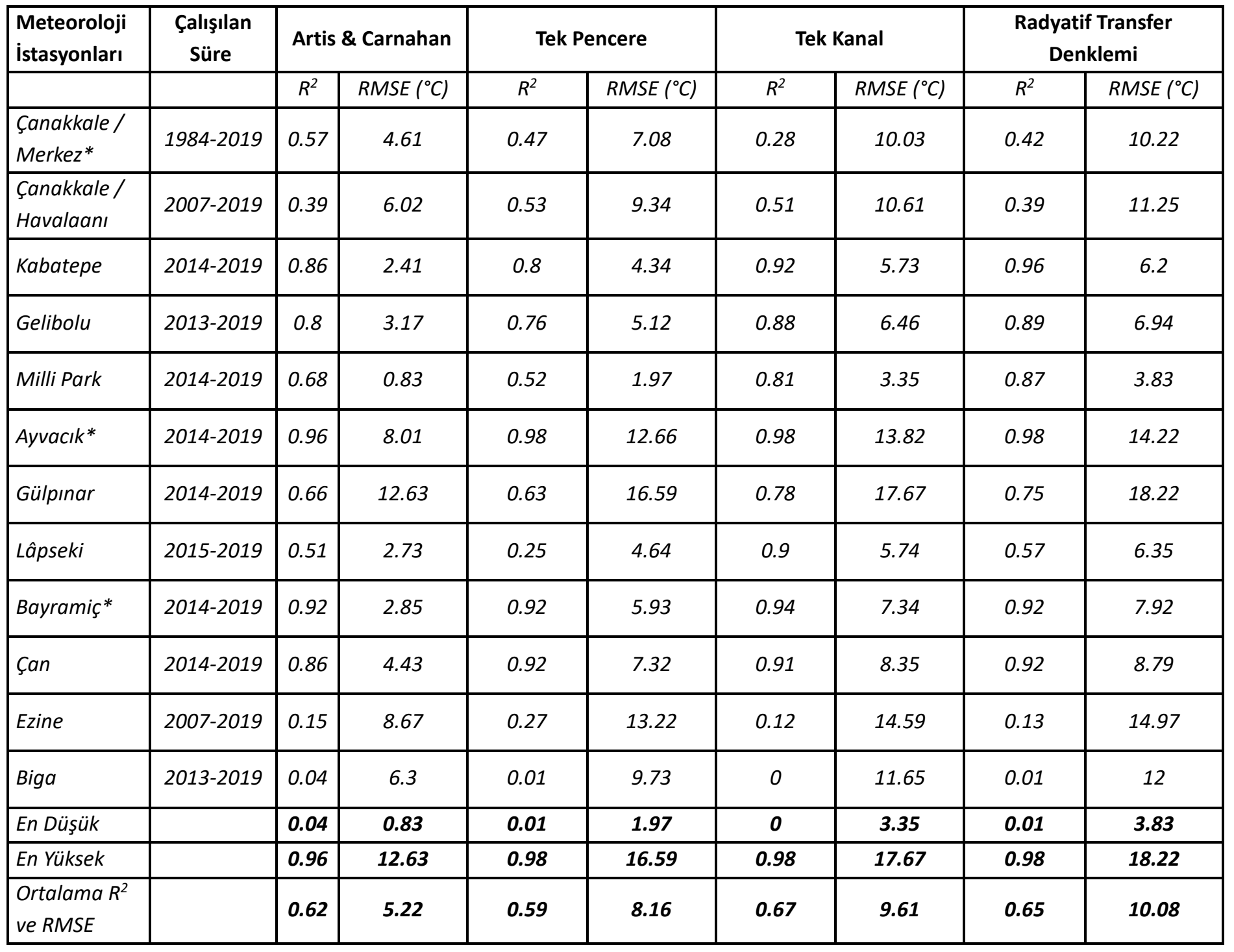

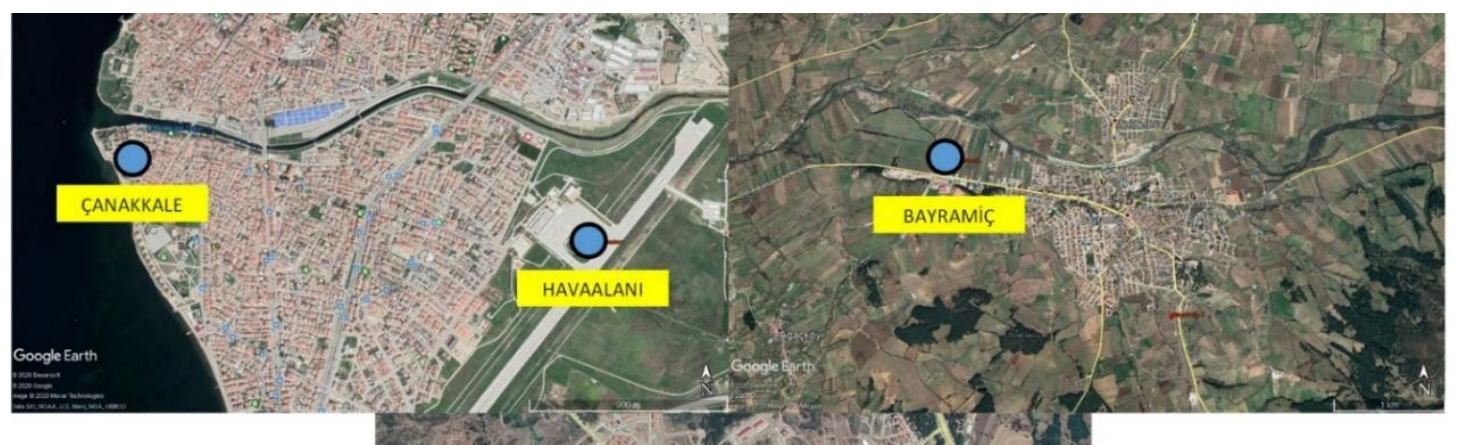

Şekil 5. YYS yöntemlerinin başarımının incelendiği meteoroloji istasyonları haritası (Görüntüler Google Earth'den temin edilmiştir) 
Termal uydu görüntülerinden herhangi bir bölgedeki ya da yerleşim alanındaki hava sıcaklığının belirlenebilmesinde en büyük ölçüt kent 1s1 ada etkisidir. Kentleşmenin yüksek olduğu bölgelerde termal uydu görüntülerinden üretilen YYS ile hava sıcaklığının sıcaklığın belirlenmesi zorlaşır. Ancak kentleşmenin düşük olduğu alanlardaki hava sıcaklığı ile termal uydu

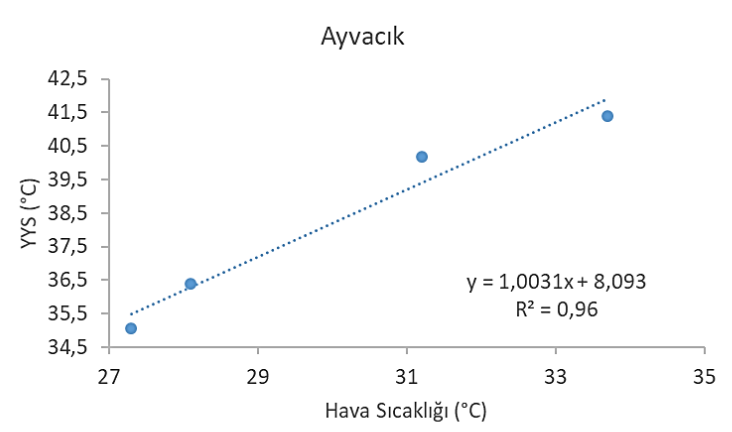

görüntülerinden üretilen YYS arasındaki ilişki daha doğru bir şekilde kurulabilir. Kent alanlarındaki meteoroloji istasyonları, kentteki farklı bileşenlerin yüzey sıcaklığını temsil etmeyebilir. Kentleşmenin düşük olduğu alanlardaki meteoroloji istasyonları, yüzey alanlarının sıcaklığını ancak belirli bir sapma değeri ile temsil edebilir.
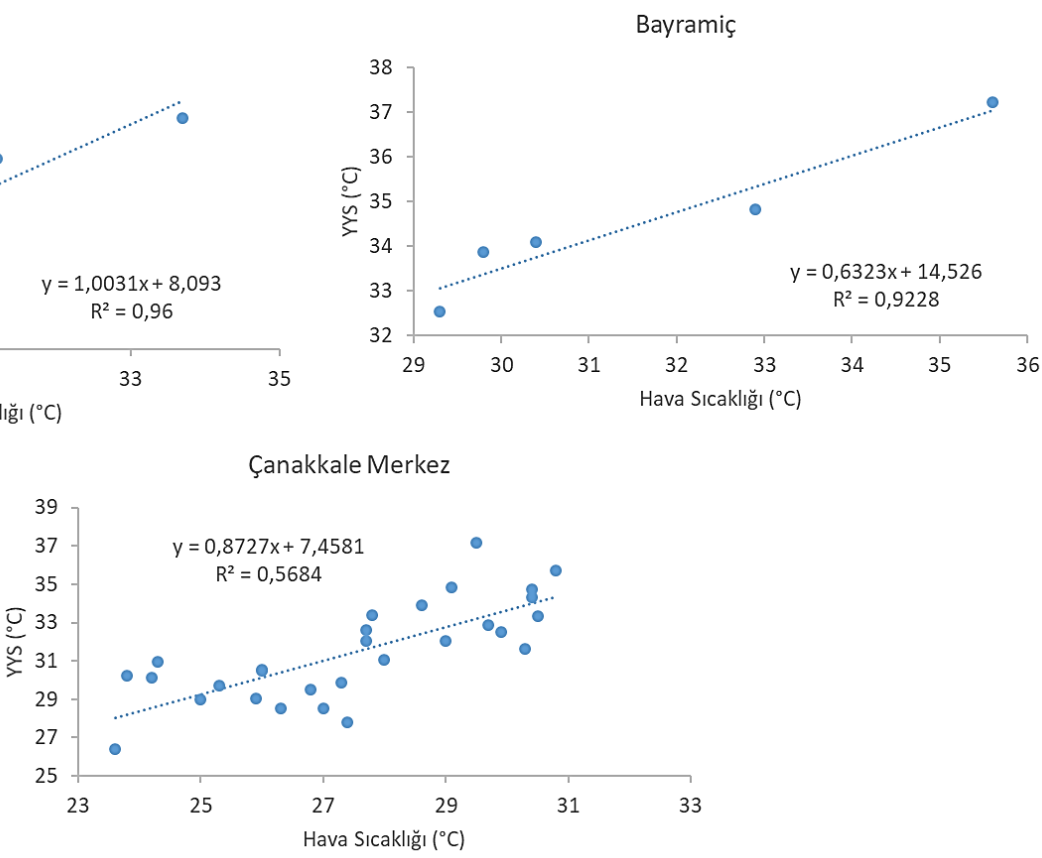

Şekil 6. Artis \& Carnahan yönteminin anlamlı ilişki grafiği oluşturduğu bölgeler
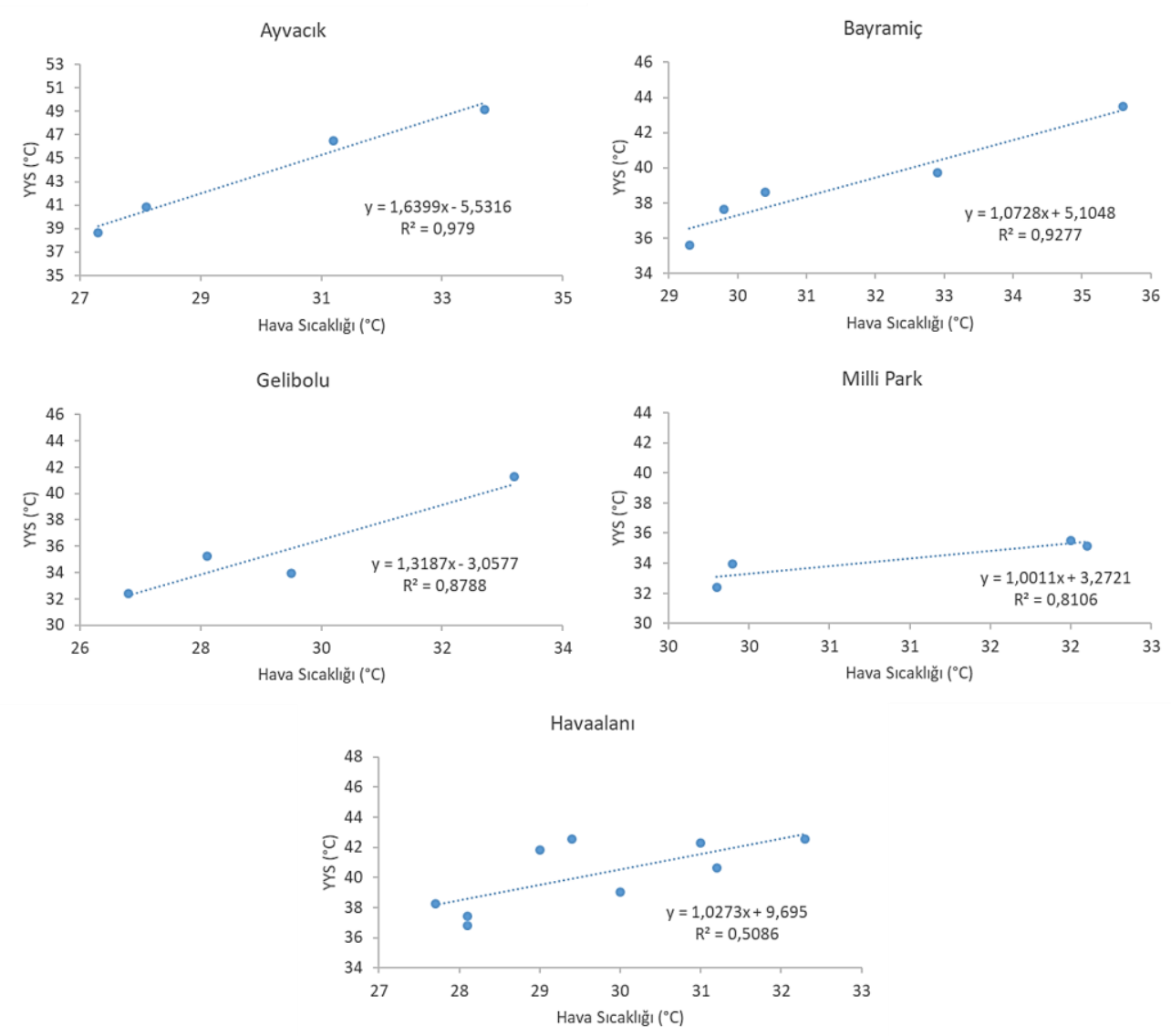

Şekil 7. Tek Kanal yönteminin anlamlı ilişki grafiği oluşturduğu bölgeler 

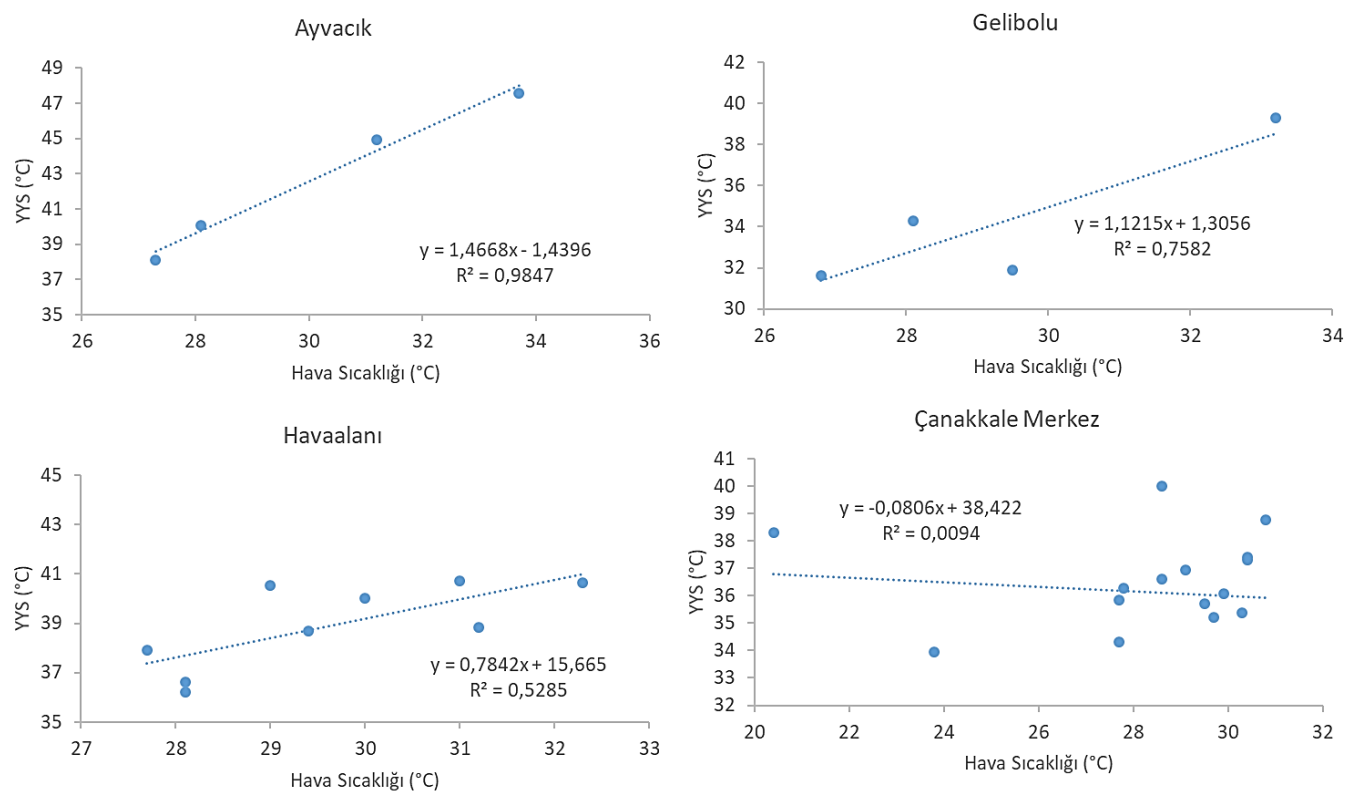

Şekil 8. Tek Pencere Yöntemi anlamll grafiği oluşturduğu bölgeler
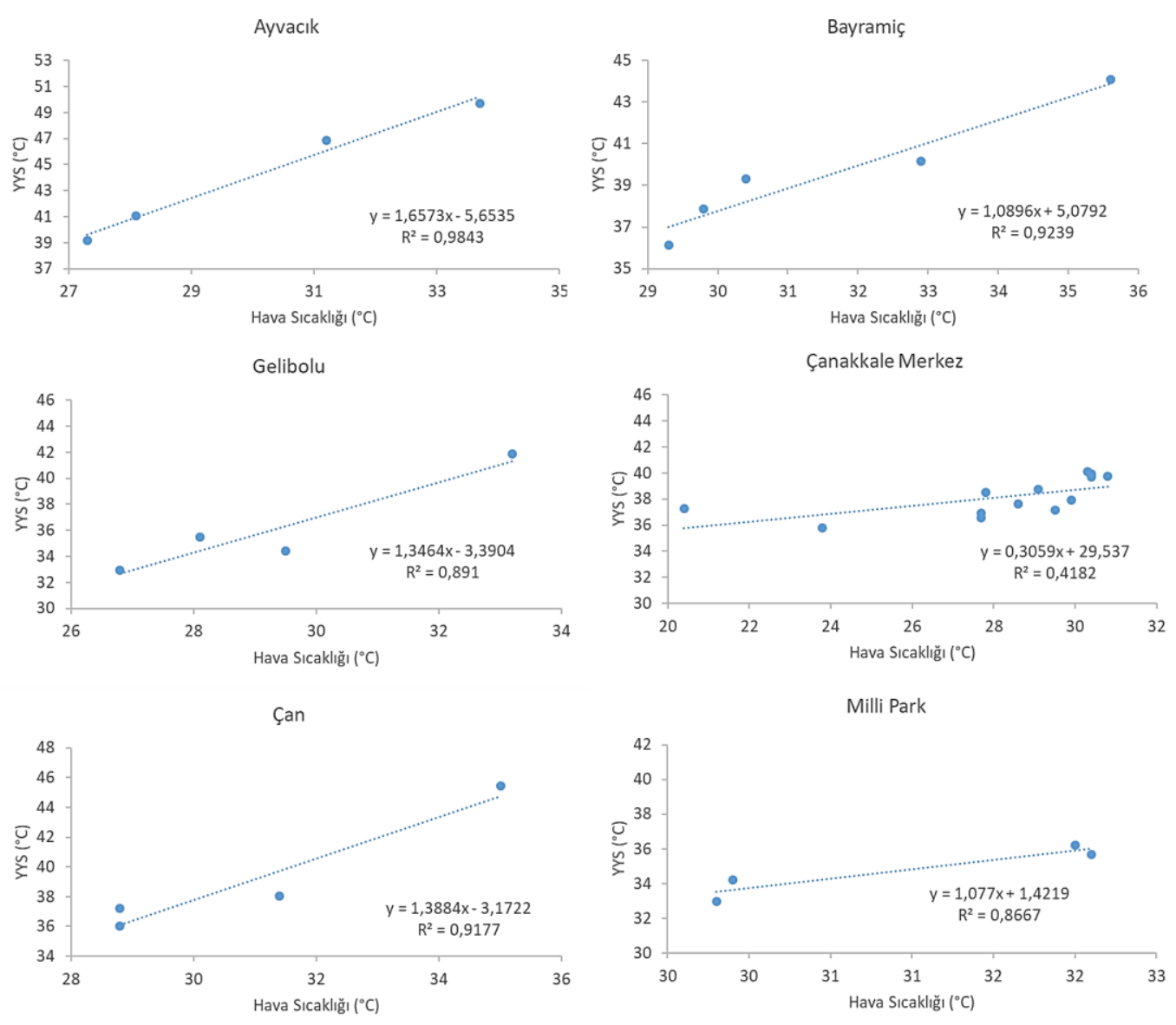

Şekil 9. Radyatif Transfer Denkleminin anlamlı ilişski grafiği oluşturduğu bölgeler 


\subsection{YYS - NDVI İlişkisi}

Her bir yöntem ile üretilen YYS ile yine istasyonlara denk gelen NDVI değerleri arasındaki ilişki incelenmiştir. NDVI indisinin arttığı bölgelerde YYS düşer (Özelkan ve ark., 2011a). Yeşil bitki örtüsünün arttığ1 alanlar, sağlıklı bitkinin yoğun olduğu alanlar sicaklığı absorbe etmektedir ve bu bölgelerdeki YYS değerleri bitki olmayan alanlara kıyasla daha düşüktür. Ínceleme alanında bitki örtüsüne yakın istasyon alanlarında NDVI ile YYS arasında negatif ilişki gerçekleşmiştir. Radyatif Transfer Denklemi ve Tek Kanal Denkleminde en iyi YYS-NDVI ilişkisi Çan ve Gelibolu, Tek Pencere denkeleminde ise Çan ve Gelibolu
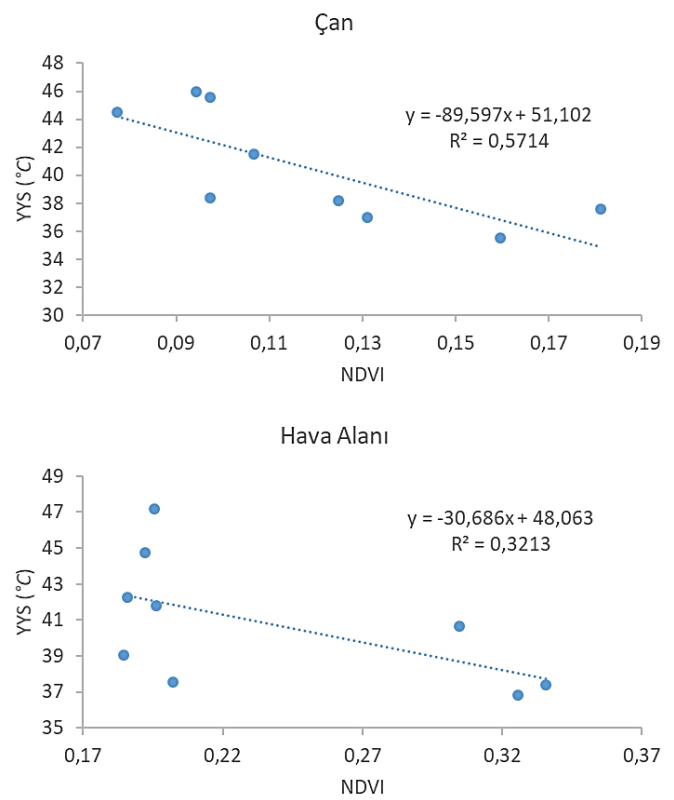

ile birlikte Biga ve Havaalanı istasyonunda gerçekleşmiştir. Tek Pencere Denklemi YYS-NDVI ilişkisini diğer yöntemlere kıyasla daha fazla istasyonda tanımlar (Havaalanı, Biga, Gelibolu, Çan, Lapseki ve Ezine). Tek Pencere Denkleminin bu ilişkiyi tanımladığı istasyonlar aynı zamanda bitki örtüsü içinde veya yakın olan alanlardır (Şekil 10, Şekil 11, Şekil 12, Şekil 13). Yeşil alanların arttığı bölgelerde YYS değeri düşer veya tam yeşil alanların azaldığı bölgelerde YYS değerleri artmaktadir.
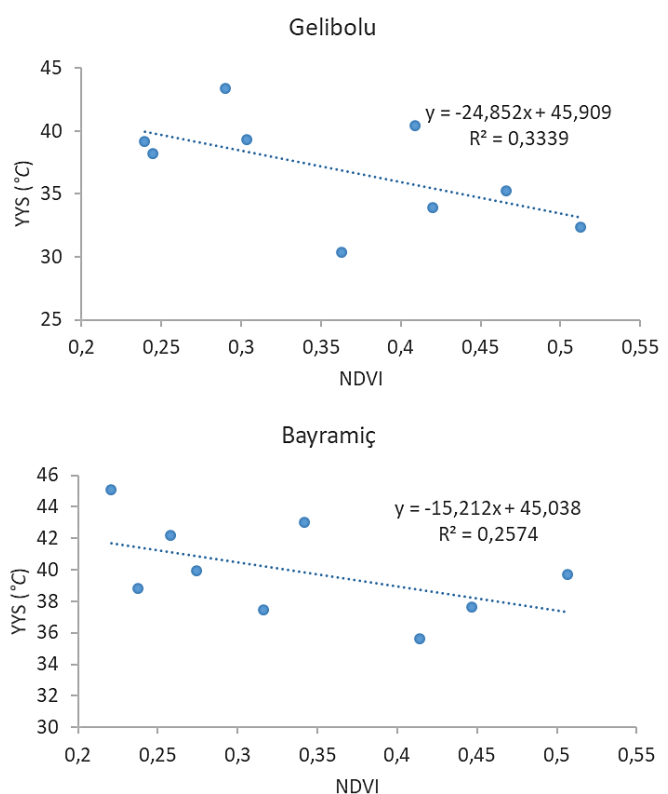

Şekil 10. Tek Kanal Yöntemi ile belirlenen YYS değerleri ile NDVI arasındaki ilişki
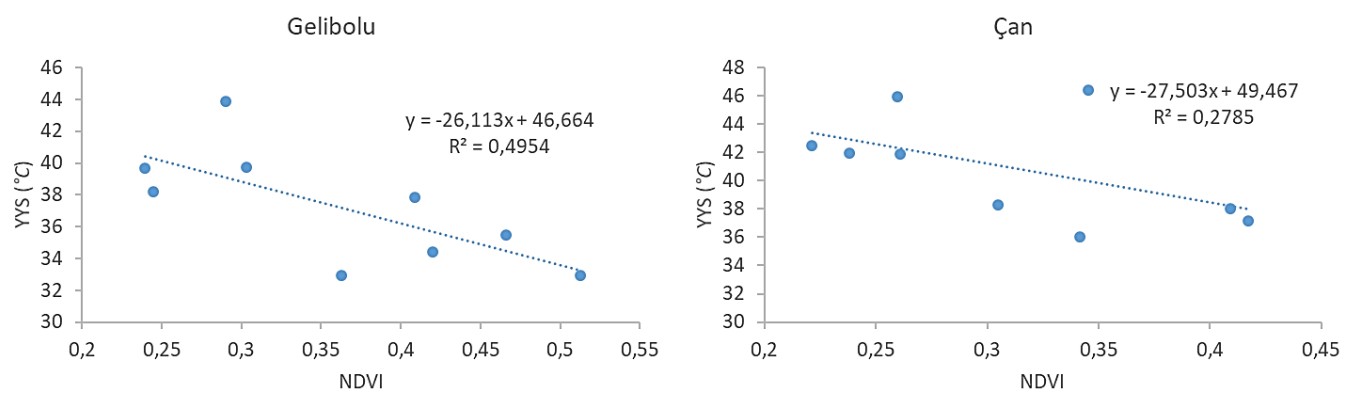

Çanakkale Merkez

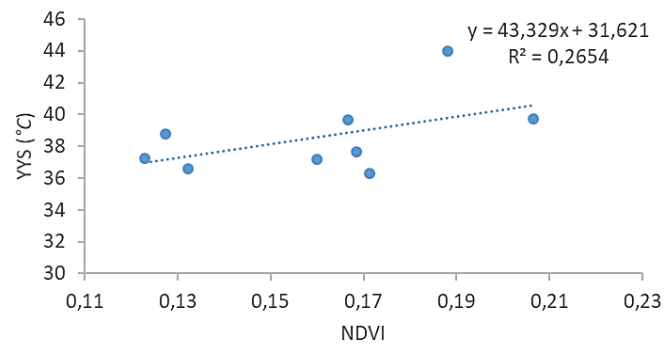

Şekil 11. Radyatif Transfer Denklemi ile belirlenen YYS değerleri ile NDVI arasındaki ilişki 

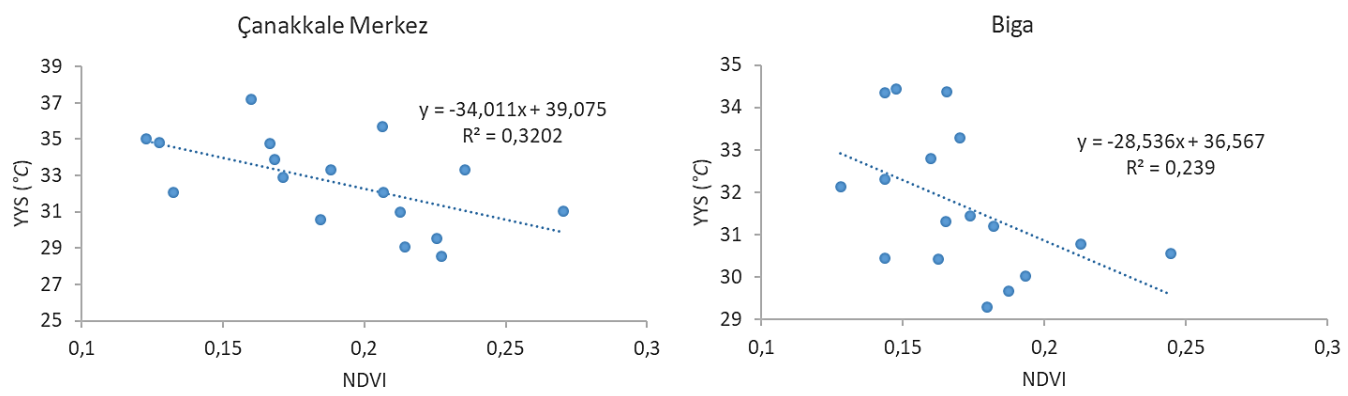

Şekil 12. Artis \& Carnahan Yöntemi ile belirlenen YYS değerleri ile NDVI arasındaki ilişki
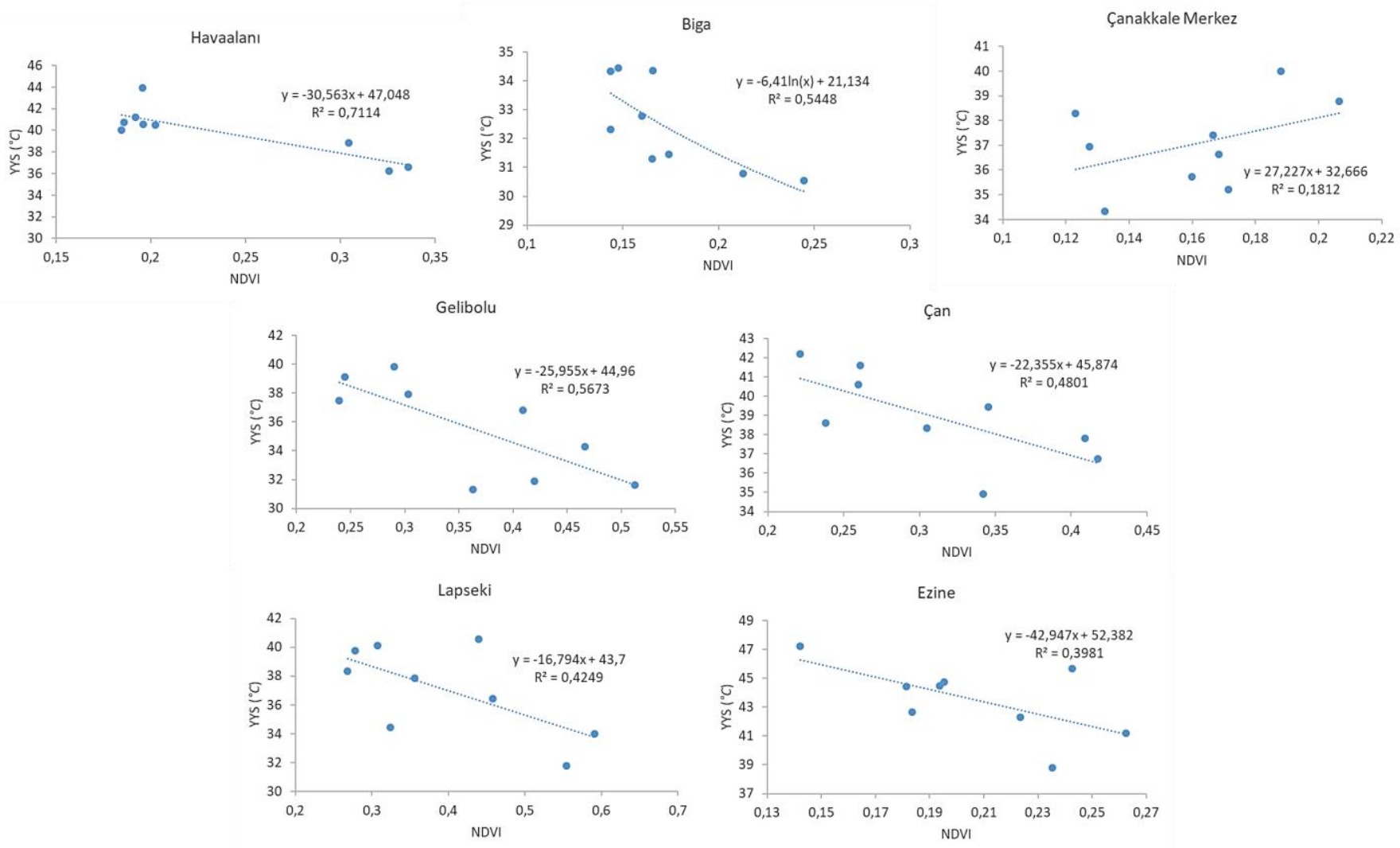

Şekil 13. Tek Pencere Yöntemi ile belirlenen YYS değerleri ile NDVI arasındaki ilişski

\section{Sonuç}

Bu çalışmada 1984 ile 2019 yılları arasında Landsat 5 TM ve Landsat 8 OLI/TIRS uyduları kullanılarak Artis \& Carnahan Denklemi, Tek Pencere Denklemi, Tek Kanal Denklemi, Radyatif Transfer Denklemi ile YYS değerleri hesaplanmıştır. Çalışmadaki YYS değerleri 12 farklı meteoroloji istasyonundan temin edilen eş zamanlı $2 \mathrm{~m}$ seviyesinde hava sıcaklığı saatlik verileri ile kıyaslanmıştır. YYS sıcaklığı ile $2 \mathrm{~m}$ seviyesindeki hava sıcaklığı ilişkisi incelenmiştir. Yöntemlerden elde edilen YYS değerleri ile $2 \mathrm{~m}$ seviyesinde hava sıcaklığı arasındaki ilişkinin R2 ve RMSE değerlerine bakılarak doğruluk analizi gerçekleştirilmiştir. Aynı zamanda YYS değerleri ile arazi örtüsü ve kullanımını ifade eden NDVI değerleri arasındaki ilişki değerlendirilmiştir. Çalışmadaki bulgulardan yola çıkılarak elde edilen sonuçlar aşağıdaki gibi sıralanabilir.

1) Artis \& Carnahan Denklemi ile üretilen YYS, $2 \mathrm{~m}$ hava sıcaklığını ortalama $5.22{ }^{\circ} \mathrm{C}$ RMSE ve $0.67 \mathrm{R} 2$ değerleri ile tahmin edebildiğinden Çanakkale ili için en başarılı yöntem olarak belirlenmiştir. YYS değerleri ile $2 \mathrm{~m}$ hava sıcaklık değerleri arasındaki sapmanın en düşük olduğu denklem $2-4{ }^{\circ} \mathrm{C}$ ile Artis \& Carnahan Denklemidir.

2) Yüksek kentleşmenin bulunduğu heterojen bölgeler (arazi örtüsü yüzey bileşenleri ve arazi örtüsü yoğunluğunun iç içe geçmiş olması) tüm yöntemlerin başarısını düşürmektedir.

3) Kent alanları dışındaki homojen yapıya sahip bölgelerde bulunan meteoroloji istasyonlarında, uydudan belirlenen YYS 
değerleri ile $2 \mathrm{~m}$ hava sıcaklığı değerleri arasında sıcaklık sapmaları meydana geldiği gözlemlenmiştir.

4) NDVI değerindeki değişimler YYS değerini doğrudan etkilemektedir. NDVI ile YYS değerleri arasında negatif korelasyon bulunmaktadır. YYS değeri yeşil alanların arttığı bölgelerde düşerken yeşil alanların azaldığı bölgelerde artmaktadir.

5) Uzaktan algılama yöntemleri ile elde edilen termal veriler ve bunlardan üretilen YYS değerleri arazi örtüsünün ve kullanımının zamansal değişiminin yorumlanmasında önemli bir kaynaktır. Yer yüzey sıcaklığı çalışmalarında (volkanik alanların belirlenmesi, doğal kaynakların belirlenmesi, orman yangını risk ve analizi, kent 1sı adası etkisi, küresel 1sınma etkisi, ziraat ürünlerinlerinin analizi, don alanlarının belirlenmesi, kuraklık analizi vb. Landsat uydu verilerinin kullanılması mümkündür.

\section{Kaynakça}

Akyürek, Ö., (2020). Termal Uzaktan Algılama Görüntüleri ile Yüzey Sicaklıklarının Belirlenmesi: Kocaeli Örneği, Artvin Çoruh Üniversitesi, Doğal Afetler Uygulama ve Araştırma Merkezi, Doğal Afetler ve Çevre Dergisi. 6(2), 377-390. Doi: $10.21324 /$ dacd.667594.

Arca, D., (2012). Afet Yönetiminde Coğrafi Bilgi Sistemleri ve Uzaktan Algılama, Karaelmas Fen ve Mühendislik Dergisi 2, ss: 53-61.

Artis, D.A. ve Carnahan, W.H., (1982). Survey of Emissivity Variability in Thermography of Urban Areas, Remote Sensing of Environment.

Aydınlı, H.İ. ve Çiftçi, S., (2015). Türkiye'de Kır-Kent Kavramlarının Değişen Niteliği ve Mevzuatın Sürece Etkisi, Elektronik Sosyal Bilimler Dergisi, 14(54), (192-200).

Ayvacı, H.Ş., ve Candaş, B., (2018). Students Understandings on Light Reflection from Different Educational Level, Journal of Computer Education Research.

Bayar R. ve Karabacak K., (2017). Ankara İli Arazi Örtüsü Değişimi (2000-2012), Coğrafi Bilimler Dergisi, 15(1), 5976.

Becker, F., (1982). Absolute Sea Surface Temperature Measurement by Remote Sensing and Atmospheric Corrections Using Differential Radiometry, In Processes in Marine Remote Sensing.

Becker, F., (1987). The İmpact of Spectral Emissivity on the Measurement of Land Surface Temperature, Quart. J.Roy Meteorologly Social.

Carlson, T. ve Ripley, D.A., (1997). On the Relation Between NDVI, Fractional Vegatation Cover, and Leaf Area Index, Remote Sensing of Environment, 62(3), 241-252p.

Chander, G., Markham, B. L., ve Helder, D. L. (2009). Summary of Current Radiometric Calibration Coefficients for Landsat MSS, TM, ETM+, and EO-1 ALI sensors. Remote sensing of environment, 113(5), 893-903.

Chedin, A., Scott, N.A., Whacihe, C., ve Moulinier, P., (1985). The İmproved Initialisation Inversion Method: A High Resolution Physical Method for Temperature Retrievals from the TIROS-N Series, Journal of Climate and Applied Meteorology.

Çelik, B., (2013). Yeryüzü Sıcaklıklarının Uzaktan Algılama Tekniği ile Belirlenmesi: Tek-Kanal Yöntemleri, İstanbul Teknik Üniversitesi Yüksek Lisans Tezi.

Dağlıyar, A., (2016). Uzaktan Algılama Çalışmalarında Termal Uygulamalar, Doğal Kay. ve Eko. Bült. (2016) 22: 109-115.
Durna, S., (2014). Denizlerdeki Yağ Tabakasının Tespitinde Radar Görüntülerinin Kullanımı, Denizcilik uzmanlık tezi.

Gorodetskii, A.K., (1985). Earth Surface Temperature Determined from Angular Radiance Distribution in Atmospheric Windows, Soviet Journal of Remote Sensing.

Hamdi, R., (2010). Estimating Urban Heat Island Effects on the Temperature Series of Uccle (Brussels, Belgium) Using Remote Sensing Data and a Land Surface Scheme, Remote Sens., 2, 2773 - 2784

Ho. D, Asem A., ve Deschamps, P.Y., (1986). Atmosheric Correction for the Sea Surface Temperature using NOAA-7 AVHRR and METEOSAT-2 inftared data, International Journal of Remote Sensing.

Jimenez - Munoz, J.C., Sobrino, J.A., (2003). A Generalized Single - Channel Method for Retrieving Land Surface Temperature from Remote Sensing Data, J. Geophys. 108(D22), 4688 doi: 10.1029/2003JD003480.

Jiménez-Muñoz, J. C., Cristóbal, J., Sobrino, J. A., Sòria, G., Ninyerola, M., \& Pons, X., (2008). Revision of the SingleChannel Algorithm for Land Surface Temperature Retrieval from Landsat Thermal-Infrared Data, IEEE Transactions on geoscience and remote sensing, 47(1), 339-349.

Kavzoğlu, T., ve Çölkesen, İ., (2011). "Uzaktan Algılama Teknolojileri ve Uygulama Alanları", Türkiye'de Sürdürülebilir Arazi Yönetimi Çalıştayı, 26-27 Mayıs 2011, Okan Üniversitesi, İstanbul.

Koçman A., (1993), Türkiye İklimi, Ege Üniversitesi Edebiyat Fakültesi, Coğrafya Bölümü, İzmir.

Lac, C., Donnelly, R.P., Masson, V., Pal, S., Riette, S., Donier, S., Queguiner, S., Tanguy, G., Ammoura, L., ve Xuref Remy, I., (2013). CO2 Dispersion Modelling over Paris Region withing the $\mathrm{CO} 2$ - Megaparis Project.

Liu, H., Sun, D., Yu, Y., Wang, H., Liu, Y., Liu, Q., Du, Y., Wang, H., Cao, B., (2014). Evalution of the VIIRS and MODIS LST products in an arid area of northwest China. Remote Sens. Environment, 142, 111-121.

Liu, L., ve Zhang, Y., (2011). Urban Heat Island Analysis Using the Landsat TM Data and Aster Data: A Case Study in Hong Kong. Remote Sens., 3, 1535-1552.

Mallick, J., Kant, Y., Bharath, B.D., (2008). Estimation of Land Surface Temperature over Delhi Using Landsat-7 ETM+, J.Ind. Geophys. Union 12(3), 131-140.

Oğuz, H., (2015). A Software Tool for Retrieving Land Surface Temperature from ASTER Imagery, Tarım Bilimleri Dergisi 21, 471-482.

Oke, T. R. (2002). Boundary layer climates. Routledge.

Özelkan, E., Papila, I., Avci, D.Z.U., Karaman, M., (2011a). Drought Determination by Using Land Surface Temperature and Normalized Difference Vegetation Index, 34th International Symposium on Remote Sensing of Environment - The GEOSS Era: Towards Operational Environmental Monitoring, Sydney, Australia, ss: 1-4.

Özelkan, E., Ormeci, C., Karaman, M., (2011b). Determination of the Forest Fire Potential by Using Remote Sensing and Geographical Information System, Case StudyBodrum/Turkey. Proceedings of the eighth International EARSeL FF-SIG Workshop Stresa (Italy (pp.51-56). Stresa, Italy.

Özelkan, E., (2014). Trakya Bölgesi Bağ Alanlarının Uzaktan Algilama ve Coğrafi Bilgi Sistemleri Teknikleri ile İncelenmesi, İstanbul Teknik Üniversitesi Doktora Tezi.

Özelkan, E., Bagis, S., Ozelkan, E. C., Üstündağ, B. B., Yücel, M., ve Ormeci, C., (2015). Spatial Interpolation of Climatic 
Variables Using Land Surface Temperature and Modified Inverse Distance Weighting, International Journal of Remote Sensing, vol.36, 1000-1025.

Özelkan, E., Sağlık, A., Sümer, S. K., Bedir, M., \& Kelkit, A., (2018). Kentleşmenin Tarım Alanları Üzerine Etkisinin Uzaktan Algılama ile İncelenmesi; Çanakkale Örneği, Çanakkale Onsekiz Mart Üniversitesi Ziraat Fakültesi Dergisi, vol.6, 123-134.

Price. J.C., (1981). The Contribution of Thermal Data in Landsat Multispectral Classifacition, Photo. English Remote Sensing.

Price, J.C., (1983). Estimation Surface Temperatures from Satellite Thermal İndrared Data Simple Formulation for the Atmospheric Effect, Remote Sensing of Environment.

Rouse Jr, J. W., (1973). Monitoring the Vernal Advancement and Retrogradation (Green Wave Effect) Of Natural Vegetation.

Salih, M. M., Jasim, O. Z., Hassoon, K. I., ve Abdalkadhum, A. J., (2018). Land Surface Temperature Retrieval from LANDSAT-8 Thermal Infrared Sensor Data and Validation with Infrared Thermometer Camera, International Journal of Engineering \& Technology, 7(4.20), 608-612.

Sensoy S., Demircan M., Ulupınar U., Balta İ., (2008). Türkiye İklimi,

https://www.mgm.gov.tr/FILES/genel/makale/13_turkiye_ iklimi.pdf, [Erişim 20 Temmuz 2020].

Rozenstein, O., Qin, Z., Dermian, Y., Karnieli, A., (2014). Derivation of Land Surface Temperature for Landsat-8 TIRS Using a Split Window Algorithm, Sensors, 14, doi: 10.3390/s140405768.

Sobrino, J.A., Jiménez-Muñoz, J.C., Paolini, L., (2004). Land Surface Temperature Retrieval from LANDSAT TM 5. Remote Sensing Environment, 90 (4), 434-440.

Sobrino, J.A., Jimenez-Muoz, J.C., Soria, G., Romaguera, M., Guanter, L., Moreno, J., Plaza, A., Martinez, P., (2008). Land surface emissivity retrieval from different VNIR and TIR sensors, IEEE Transactions on Geoscience and Remote Sensing, 46(2), 316-327.

Stathopoulou, M., \& Cartalis, C., (2007). Daytime Urban Heat Islands from Landsat ETM+ and Corine Land Cover Data: An Application to Major Cities in Greece, Solar Energy, 81(3), 358-368.

Şahin, M., Yıldız, B.Y., Şenkal, O., Peştemalci, V., (2001). Uydu Verileri Kullanılarak İzmir Şehir Merkezinin Yer Yüzey Sıcaklığının Tahmini, Süleyman Demirel Üniversitesi, Fen Bilimleri Enstitüsü Dergisi 15-1(2001), 36-45.

Şekertekin, A., Kutluoğlu, Ş.H., Kaya, Ş., Marangoz, A.M., (2015). Uydu Verileri ile Arazi Örtüsündeki Yer Yüzey S1caklığı Değişimlerinin Analizi: Zonguldak Örneği,
Türkiye, TMMOB Harita ve Kadastro Mühendisleri Odas1, 15. Türkiye Harita Bilimsel ve Teknik Kurultayı, 25-28 Mart 2015, Ankara.

Şekertekin, A., Çiçekli, S.Y., Arslan, N., (2018). Gece ve Gündüz Yer Yüzey Sicaklığı Görüntüleri ile Yüzey Isı Adası Analizi, VII. Uzaktan Algılama Ve CBS Sempozyumu (UZAL-CBS 2018) Eskişehir / Türkiye.

Şekertekin, A. ve Bonafoni, S., (2020). Land Surface Temperature Retrieval from Landsat 5, 7, and 8 over Rural Areas: Assessment of Different Retrieval Algorithms and Emissivity Models and Toolbox Implementation, Remote Sensing.

USGS. (2016). Landsat 8 (L8) data users handbook, Department of the Interior US Geological Survey, LSDS-1574.

Yaylı, H., (2012). Çevre Etiği Bağlamında Kalkınma, Çevre ve Nüfus. Süleyman Demirel Üniversitesi Sosyal Bilimler Enstitüsü Dergisi, Y1l: 2012/1, Say1: 15

Yüksel Ü.D. ve Yılmaz, O., (2008). Ankara Kentinde Kentsel Isi Adasi Etkisinin Yaz Aylarinda Uzaktan Algilama Ve Meteorolojik Gözlemlere Dayali Olarak Saptanmasi Ve Değerlendirilmesi, Gazi Üniv. Müh. Mim. Fak. Der. Cilt 23, No 4, 937-952, 2008.

Yomralığlu, T., (2000). "Coğrafi Bilgi Sistemleri Temel Kavramlar ve Uygulamalar", Akademi Kitabevi, 2. Bask1.

Zhou, J., Chen, Y., Wang, J., Zhan, W., (2011). Maximum Nighttime Urban Heat Island (UHI) Intensity Simulation By Integrating Remotely Sensed Data and Meteorological Observations, IEEE J. Sel. Top. Appl. Earth Obs. Remote Sens., 4, $138-146$.

Weng, Q., (2009). Thermal Infrared Remote Sensing for Urban Climate and Environmental Studies: Methods Applicaitons, and Trends. ISPRS J. Photogramm, 64, 335-344.

Qin, Z., Karnieli, A., Berliner, P.A., (2001). Mono - Window Algorithm for Retrieving Land Surface Temperature from Landsat TM Data and Its Application to the Israel - Egypt Border Region, Int. J. Remote Sen. 2001, 22, 3719- 3746.

URL 1, http://tuik.gov.tr/UstMenu.do?metod=temelist Son Erişim: 07.09.2020.

URL 2, https://tr.wikipedia.org/wiki/Kaz_Da\%C4\%9F\%C4\%B1 Son Erişim: 18.09.2020.

URL 3, https://www.mgm.gov.tr/veridegerlendirme/il-ve-ilceleristatistik.aspx $\mathrm{k}=\mathrm{H} \& \mathrm{~m}=\mathrm{CANAKKALE}$ Son Erişim: 20.09.2020.

URL 4, http://tuik.gov.tr/UstMenu.do?metod=temelist Son erişim: 07.09.2020. 